\title{
ARTICULO ORIGINAL-2016: Perfil epidemiológico y respuesta terapéutica de la infección por Cryptococcus sp. en pacientes de Costa Rica en el Hospital San Juan de Dios, Período 2008-2012
}

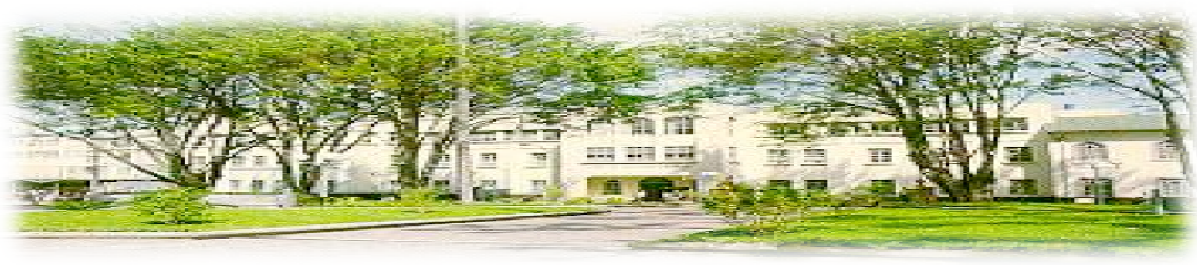

Hospital San Juan de Dios, San José, Costa Rica. Fundado en 1845

\section{ISSN}

2215-2741
Recibido:

Aceptado:
$14 / 08 / 2015$

$05 / 11 / 2015$

Diego Ávila Sánchez ${ }^{1}$

Manuel Antonio Villalobos Zúñiga ${ }^{2}$

\begin{abstract}
${ }^{1}$ Médico especialista en Medicina Interna, departamento de Infectología y Medicina Interna, Hospital San Juan de Dios, CCSS. Correo electrónico: diegoavilasan@gmail.com

${ }^{2}$ Médico especialista en Medicina Interna e Infectología, Departamento de Infectología Hospital San Juan de Dios, CCSS. Correo electónico: manue1701@gmail.com
\end{abstract}

\section{RESUMEN}

\section{Antecedentes:}

La criptococosis es una micosis invasiva causada principalmente por Criptococcusneoformans. Esta enfermedad afecta sobre todo a pacientes inmunosuprimidos, particularmente pacientes con infección por VIH pero también puede afectar inmunocompetentes. Las formas de presentación clínica más frecuentes son meningitis y afectación pulmonar.

\section{Metodología:}

En este trabajo se pretende determinar el perfil epidemiológico, las características clínicas y la respuesta al tratamiento de los pacientes con criptococosis en el Hospital San Juan de Dios, período 2008-2012; diagnosticados en el laboratorio de bacteriología del hospital. Se obtienen los datos mediante un estudio observacional de revisión de expedientes de una muestra final de 33 expedientes.

\section{Resultados:}

De la muestra analizada un $78,8 \%$ fue del género masculino con una mediana de edad de 40,1 \pm 
11.9 años. El $72,7 \%$ tenía enfermedad por VIH, $20 \%$ inmunocompetentes y $9.1 \%$ inmunosupresión farmacológica sobre todo por patologías autoinmunes. La presentación clínica fue $72.7 \%$ como meningitis, $12.2 \%$ pulmonar, $9.1 \%$ forma diseminada y $6.1 \%$ forma cutánea. La forma meníngea predominó en pacientes con VIH y la pulmonar en inmunocompetentes. La especie identificada fue C. neoformans $87.9 \%, C$. laurentii $9.1 \%$ y $C$. uniguttulatus 3\%.La tinta china como método diagnóstico mostró una sensibilidad de $25 \%$ en VIH negativos y $58 \%$ en VIH positivos. Se le suministró anfotericina B deoxicolatoal $100 \%$ de los pacientes con VIH y $44 \%$ de los VIH negativos. El $30 \%$ de los pacientes con VIH falleció y ninguno de los VIH negativos.

\section{Conclusiones:}

La criptocosis es una micosis que afecta fundamentalmente adultos jóvenes inmunocomprometidos, particularmente en pacientes VIH positivos en fase de SIDA. Meningitis es la presentación más frecuente, y la forma pulmonar predominó en inmunocompetentes. Todos los pacientes coinfectados recibieron anfotericina B deoxicolato de tratamiento y aún así tuvieron una mortalidad de $30 \%$.

\section{ABREVIATURAS}

VIH, virus de inmunodeficiencia humana; TARV, tratamiento antiretroviral; SIDA, síndrome de inmunodeficiencia adquirida.

\section{PALABRAS CLAVE}

Criptococosis, perfil epidemiológico, respuesta terapeútica

\section{ABSTRACT}

\section{Background:}

Cryptoccosis is an invasive mycosis due to Criptococcus neoformans. This infection affect mainly inmunosupromised patients, particularly with HIV, and also may occur in inmunocompetents. The most common clinical presentation are meningitis and pulmonary.
Methods and materials: This work is aim to determinate the therapeutic response of the patients with cryptococcosis in Hospital San Juan de Dios, in a period between 2008-2012; with the diagnosis made in the bacteriology laboratory. The data was obtained by an observational study of medical file of 33 patients.

Results: $78,8 \%$ of the patients were male with an age average of $40,1 \pm 11.9$ years. $72,7 \%$ were VIH positive, $20 \%$ were inmunocompetents and $9.1 \%$ with therapeutic inmunossupression due mainly to autoinmune disorders. The clinical presentation were $72.7 \%$ with meningitis, $12.2 \%$ pulmonar, $9.1 \%$ disseminated and $6.1 \%$ cutaneous. Meningeal presentation was predominant in HIV positives and pulmonary in inmunocompetents. The predominant species was $C$. neoformans in $87.9 \%, C$. laurenti in $9.1 \%$ and C. uniguttulatus in $3 \%$. The indian ink as diagnostic tool had a sensibility of $25 \%$ in HIV negative and $58 \%$ en HIV positives. $100 \%$ of HIV patients and $44 \%$ of HIV negatives were given with anphotericin B deoxycolate as initial treatment. The $30 \%$ of HIV patients die and none of HIV negatives.

Conclusions: Cryptococcosisis a fungal disease that affect mainly young adults inmunocompromised with HIV at AIDS phase. Meningitis is the most frequent form in HIV patients and pulmonary was in inmunocompetents.All the coinfected patients were given with anphotericin B deoxycolateand in spite of that they had a $30 \%$ mortality.

\section{KEY WORDS}

Cryptococcosis, epidemiological features, therapeutic response

\section{DISCUSIÓN}

\section{Concepto}

La criptococosis es una micosis sistémica de distribución mundial causada principalmente por el Cryptococcusneoformansque afecta en su mayoría a individuos inmunocomprometidos. La misma se asocia a una significativa morbilidad y mortalidad entre la población infectada. 


\section{Historia}

La primera identificación del Cryptococcussp. en el ambiente se hizo por Sanfelice en 1894, en un jugo de pera en Italia (1). Un año después, Busse y Buschke ${ }^{(2)}$ de manera independiente reportaron el primer caso de criptococosis humana en una mujer joven que desarrolló una úlcera cutánea crónica sobre su tibia, con levaduras identificadas posteriormente en la autopsia. Esta misma levadura también se encontró en múltiples órganos de su cuerpo. En 1914, Versé describe el primer caso de meningitis por criptoco$\cos$.

Durante los primeros años de criptococosis clínica, existían varios nombres para la misma levadura, Saccharomyces neoformans, Cryptococcus hominis, and Torula histolytica. En 1935, Benham categoriza estas levaduras, con base en su morfología, fermentación y serologías. El nombra a la levadura $C$. hominis y a la enfermedad, criptococosis ${ }^{(3)}$. Posteriomente el nombre fue cambiado a $C$. neoformans debido a prioridad temporal, y a que Sanfelice utilizó inicialmente el término neoformans.

En el año 2002 se definen dos variedades, Cryptococcus neoformans var. neoformans (serotipo D) y Cryptococcus neoformans var. grubii (serotipo A) y otra especie, Cryptococcus gattii(serotipos B y C).

En el 2005, la secuencia genómica del Cryptococcus neoformans fue revelada ${ }^{(4)}$.

\section{Microbiología}

\section{Taxonomía}

El género Cryptococcus comprende 19 especies, caracterizadas como variedades de levaduras encapsuladas. Han existido reportes anecdóticos de infecciones humanas causadas por especies no-neoformans; como Cryptococcus albidus y Cryptococcus laurentii ${ }^{(5,6)}$. Sin embargo, estos reportes clínicos son muy poco comunes, con infecciones pobremente documentadas. De tal manera, que cualquier infección causada por especies de criptococo diferentes a $C$. neoformans y $C$. gattii requieren una rigurosa evidencia histopatológica y de cultivo de la infección.

El Cryptococcus neoformans y el C. gattii pertenecen al grupo de los basidiomicetes, y son levaduras encapsuladas. Ambas se sublcasifican en cuatro serotipos y constituyen dos especies distintas. Los serotipos son basados en las reacciones de aglutinación capsular y se designan A, B, C o D. Los criptococos con los serotipos A y D se ubicaban en el pasado en la especie neoformans. Sin embargo, basado en diferencias genotípicas, el criptococo serotipo $A$ se considera actualmente una variedad separada, la variedad grubii $^{\text {(7). }}$. El serotipo D se clasifica en la variedad neoformans y se dividen en cuatro tipos moleculares (VNI, VNII, VNIII, VNIV). Por otra parte, los serotipos B y C se agrupan en la especie Cryptococcus gattii ${ }^{(8)}$, y se dividen subsecuentemente en cuatro tipos moleculares (VGI,VGII, VGIII, VGIV).

La presentación clínica de la criptococosis, independientemente de la especie etiológica, es generalmente indistinguible ${ }^{(9)}$.

\section{Ciclo de vida}

El ciclo del C. neoformans involucra formas asexuales y sexuales. La forma asexual existe en forma de levadura y se reproduce por gemación. Estas formas haploides y unicelulares, son las únicas formas de C. neoformans y $C$. gattii encontradas en las infecciones humanas.

El estado sexual del C. neoformans y C. gattii se observa solo in vitro.

\section{Crecimiento e identificación}

El C. neoformans y C. gattii producen colonias blancas y mucoides en una variedad de agares que usualmente son visible a las 48 horas. La identificación de ambas especies en el laboratorio clínico inicia con el aislamiento de una levadura encapsulada, ureasa-positiva. Luego la confirmación se alcanza con pruebas bioquímicas que detectan la enzima fenol oxidasa, que es únicamente producida por el $C$. neoformans y $C$. gattii.

\section{Identificación histológica}

El criptococo puede ser identificado en muestras de tejido utilizando la tinción de metenamina de plata. La tinción de mucicarmina identifica tanto la levadura como la cápsula, y es específica para Cryptococcus. La tinción de Fontana-Masson revela la melanina contenida dentro de la levadura. 


\section{Cápsula}

La cápsula de polisacárido que envuelve al $C$. neoformans y $C$. gattii se puede visualizar con tinta china cuando se examina mediante un microscopio. El grosor de la cápsula puede variar, pero puede compromenter más del $50 \%$ del diámetro de la levadura.

La cápsula tiene propiedades antifagocíticas y es un determinante importante de virulencia ${ }^{(6)}$. Los criptococos que son hipocapsulares o acapsulares son menos virulentos que las cadenas encapsuladas, según lo demuestran algunos modelos animales.

\section{Producción de Melanina}

La presencia de la enzima fenol oxidasa en el $C$. neoformans es única entre los miembros de su género. Esta enzima cataliza la conversión de compuestos fenólicos a melanina.

La enzima fenol oxidasa es un importante factor de virulencia en la criptococosis. Los criptococos mutantes que carecen de la actividad de la fenol oxidasa son avirulentos en modelos animales y más suceptibles a la fagocitosis mediada por anticuerpos ${ }^{(10)}$.

La fenol oxidasa puede promover la virulencia mediante varios mecanismos:

- Altos niveles de dopamina en el sistema nervioso central puede servir de sustrato para la producción de melanina en el organismo. Entonces, la habilidad para degradar catecolaminas protege a la levadura de los efectos tóxicos de las catecolaminas en el sistema nervioso central ${ }^{(11)}$.

- La melanina es un antioxidante que se produce y acumula en la pared celular de la levadura, protegiéndola contra la inmunidad celular y productos oxidativos ${ }^{(12)}$.

\section{Ecología}

Existen diferencias significativas en la ecología de las especies responsables de la criptococcosis.

C. neoformans var grubii y var neoformans C. neoformans var grubii y neoformans se han encontrado en muestras de polvo de áreas frecuentadas por aves, especialmente gallinas $\mathrm{y}$ palomas ${ }^{(13)}$.
La causa de la asociación de las palomas con el C. neoformans var neoformans no está del todo dilucidada. Las palomas no se infectan por el C. neoformans en la naturaleza. Dicho hongo es inhibido dentro del organismo de la paloma probablemente por su elevada temperatura corporal (mayor a $40^{\circ} \mathrm{C}$ ); sin embargo el tracto gastrointestinal de dicha ave es reservorio de la levadura en su forma saprófita.

Es posible que las palomas entren en contacto con el $C$. neoformans var grubii y nar neoformans al comer vegetación contaminada. La infección humana puede resultar de una exposición similar.

C. gattii - C. gattii se ha cultivado en diferentes especies de árboles: Eucalyptus camaldulensis y Eucalyptus tereticornis, principalmente en Australia y Nueva Zelanda ${ }^{(14,15)}$. Estos árboles son exportados desde Australia a diferentes partes del mundo, y las cadenas de Cryptococcus gattii se han aislado también en este tipo de árboles en Estados Unidos y Canadá. C. gattii no se ha cultivado aún en el guano de pájaros.

Desde 1999 se han reportado brotes de infección por C. gattii en Vancouver, Oregon, Washington, California y Idaho ${ }^{(16)}$. La mayoría de los pacientes eran inmunocompetentes y tenían compromiso pulmonar.

Aunque las infecciones causadas por C. Gattii típicamente ocurren en huéspedes aparentemente sanos; también se han reportado en inmunocomprometidos, especialmente coinfectados por el virus inmunodeficiencia humana.

Además, las infecciones del sistema nervioso central causadas por $C$. Gattii están asociados con más complicaciones neurológicas (desarrollo de criptococomas) y una respuesta tardía a la terapia en comparación con las infecciones por C. neoformans.

En nuestro país se han identificado algunos casos de infección por C. gattii ; sin embargo no existen estudios epidemiológicos que identifiquen factores de riesgo comunes entre estos pacientes así como cual fue la evolución de la enfermedad y respuesta a tratamiento.

\section{Epidemiología}

La critococosis es una infección diseminada a nivel mundial. Estudios epidemiológicos sugie- 
ren que hay aproximadamente un millón de casos por año en el mundo, con alrededor de 700000 muertes ${ }^{(17)}$

La mayoría de los casos de criptococosis ocurren en pacientes inmunocomprometidos, por lo que es frecuente su asociación con: infección por virus de inmunodeficiencia humana (VIH), sindrome de inmunodeficiencia adquirida (SIDA), terapia prolongada con esteroides, transplante de órganos, enfermedad neoplásica, sarcoidosis, síndrome hiper IgM, síndrome hiper IgE, terapias con anticuerpos monoclonales (infliximab, adalimumab, etanercept, otros), cirrosis hepática, etc.

Un estudio epidemiológico realizado en Estados Unidos del año $1992^{(18)}$, determinó una incidencia de 4.9 casos de criptococosis por cada 100000 personas. Tanto el SIDA como la etnia afroamericana eran factores riesgo asociados de forma independiente con dicha infección.

La criptococosis es la cuarta infección oportunista más común en pacientes con SIDA. Aproximadamente el 6-10\% de los pacientes con SIDA en la era previa al tratamiento antiretroviral (TARV) eran diagnosticados con criptococosis. Con el desarrollo del TARV, en los países desarrollados, durante el siglo XXI, la incidencia de criptococosis ha declinado y alcanzado un número estable de nuevas infecciones por año. Dentro de la población con SIDA, la criptococosis representa una infección que identifica un paciente con VIH no tratado o no diagnosticado.

En países en desarrollo con epidemias VIH, como en Africa Sub-Sahariana, la cirptococosis alcanza prevelencias muy altas. Algunos reportes indican que $15-45 \%$ de los pacientes con infección avanzada por VIH fallecen a causa de criptococosis ${ }^{(19)}$.

La criptococosis también tiene una tasa de infección alta en otros dos grupos mayores de riesgo, pacientes con cáncer y receptores de transplantes de órganos sólidos. Un estudio retrospectivo de reportes de casos de un solo centro de cáncer entre 1989 y 1999 reportó uina incidencia de criptococosis de 18 casos por cada 100000 admisiones, y la incidencia aumentaba con el uso de inhibidores de inmunidad celular como alemtuzumab y fludarabina en el manejo de algunas enfermedades neoplásicas ${ }^{(20)}$. En pacientes transplantados, un estudio determinó que la criiptococosis ocurrió en el 2,8\% de todos los receptores de transplantes de órganos sólidos (21). Los transplantes de hígado y riñón son los que confieren mayor riesgo de criptococosis ${ }^{(22)}$. Por el contrario, en trasplantados de médula ósea, pacientes que presentan incidencias altas de infecciones micóticas, la criptococosis es poco común.

A pesar de la asociación del criptococo con el guano de paloma, la transmisión directa de palomas a humanos no ha sido reportada. La diseminación de la infección de persona a persona tampoco ha sido documentada. Sin embargo, existe un consenso general que la mayoría de las infecciones por criptococo se deben primariamente a inhalación de partículas infecciosas, y que ocasionalmente hay casos de inoculación traumática a través de objetos ambientales o de laboratorio contaminados. Existe la hipótesis que se necesitan levaduras deshidratadas y pobremente encapsuladas o basidiosporas ( $<5$ micras $)$, para el depósito alveolar en los pulmones.

\section{Patogénesis}

La patogénesis de la criptococosis está determinada por tres factores

a) Estado inmunológico del huésped

b) Virulencia de la cadena del criptococo

c) Tamaño del inóculo

Un probable escenario es que un huésped susceptible se pone en contacto con el criptococo del ambiente mediante la inhalación de partículas infecciosas. En el alveolo, la levadura entra en contacto con los macrófagos alveolares, los cuáles reclutan otras células inflamatorias mediantes citoquinas y quimioquinas, desencadenado una respuesta TH1 y de inflamación granulomatosa. Acá la infección puede tomar una de tres vías posibles:

1. En el paciente inmunocompromeetido, las levaduras proliferan y se diseminan, causando enfermedad clínica.

2. La respuesta inmune efectiva elimina completamente la levadura del huésped.

3. Las levaduras producen un pequeño complejo linfadenopático en el pulmón, y permanece latente en el tejido, con el desarrollo de granulomas. 
El tercer escenario puede ser muy común. Baker et al, demostraron en un estudio de pacientes asintomáticos la existencia de un foco pulmonar y adenopatías hiliares que contenían levaduras ${ }^{(23)}$. Las mismas permanecían latentes y el huésped asintomático hasta la pérdida de la inmunidad local (vih, uso esteroides, tec). En ese momento las levaduras empezaban a replicarse y eventualmente se diseminaban extrapulmonarmente en distintos órganos. La fisiopatología es similar a la reactivación descrita en la tuberculosis e histoplasmosis.

\section{Manifestaciones clínicas}

Las manifestaciones clínicas de criptococosis reflejan el sitio de infección micótica, y los sitios más comúnmente afectados son el pulmón y el sistema nervioso central.

En un estudio cohorte de pacientes VIH negativos con criptococosis ${ }^{(24)}$, el $36 \%$ correspondían a afección pulmonar y el $51 \%$ a meningitis.

Sin embargo, se debe anotar que el C. neoformans puede infectar cualquier órgano del cuerpo (piel, ojos, tracto genitourinario, hueso y articulaciones, músculo, corazón, tracto gastrointestinal, mama, tiroides, suprarrenales, cabeza y cuello). Y en pacientes inmunosuprimidos puede existir afección multisitémica.

La afección del sistema nervioso central se manifiesta generalmente mediante síntomas y signos de meningitis crónica como cefalea, fiebre, letargo, déficit sensorial y de la memoria, paresia de pares craneales, deficiencia visual y signos de irritación meníngea.

La criptococosis pulmonar suele manifestarse en forma de tos, aumento en producción de esputo y dolor torácico. Los pacientes con $C$. gattii pueden presentar tumoraciones pulmonares granulomatosas conocidas como criptococomas.

Las lesiones cutáneas están presentes en el $10-15 \%$ de las formas diseminadas y pueden adoptar diversos tipos (pápulas, pústulas, nódulos o úlceras); inclusive a menudo simulan las del molusco contagioso.

\section{Diagnóstico}

Requiere la demostración del C. neoformans en tejidos que suelen ser estériles.

Examinación microscópica: el simple procedimiento de mezclar tinta china con fluidos biológicos para identificar las levaduras encapsuladas de 5-10 micras continúa siendo un método rápido y efectivo de diagnóstico para meningitis criptococóccica (ver figura 1).

Figura 1. Preparación en tinta china para líquido cefalorraquídeo en paciente con meningitis por criptococos. Ver levaduras encapsuladas

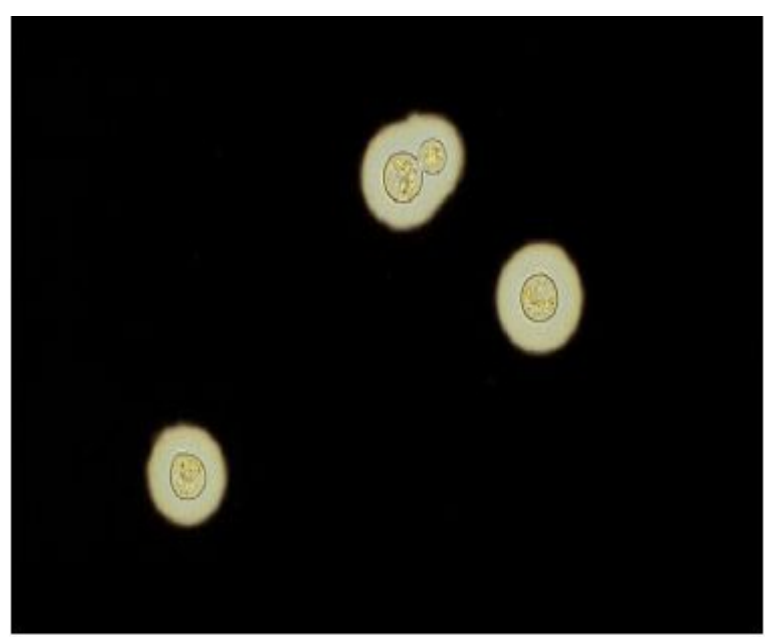

Entre los pacientes con meningitis criptococóccica, el $50 \%$ de los pacientes sin SIDA y aproximadamente el $80 \%$ de los pacientes con SIDA tienen tintas china positivas para Cryptococcus $s p$. Se requiere de un ojo entrenado para evidenciar las levaduras.

La cápsula de polisacárido puede ser identificada utilizando tinciones como mucicarmina y azul Alciano, y la hablidad para producir melanina puede ser detectada con tinción de FontanaMasson (ver figura 2)

Figura 2. Tinción de azul alciana en tejido pulmonar de paciente con neumonía por criptococos. Ver las cápsulas de polisacárido teñidas de azul. 


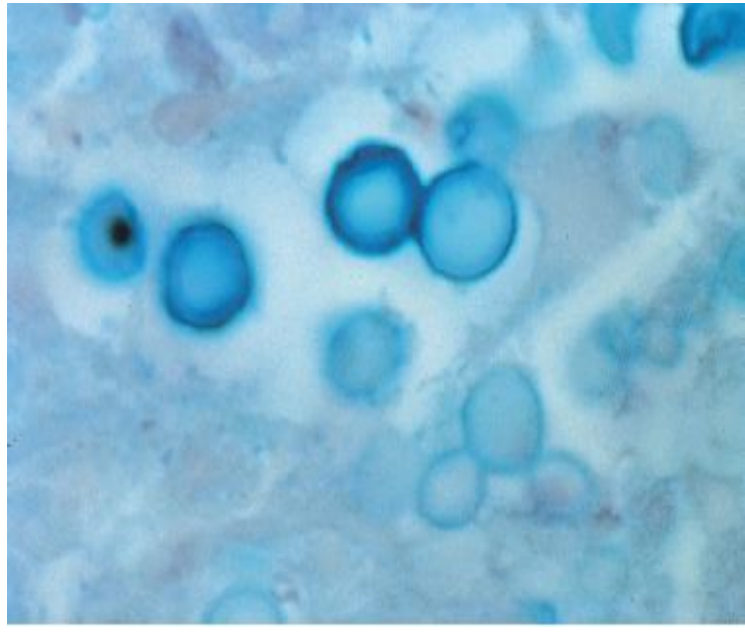

Tanto las biopsias como las citologías son útiles en diagnóstico de criptococosis.

Cultivos: el C. neoformans puede crecer en la mayoría de medios para bacterias y hongos. Generalmente es aislado 3 a 7 días después de que la muestra es colocada en el medio de cultivo, usualmente agar sangre o Sabouraud. Las levaduras aisladas pueden ser identificadas mediante reacciones bioquímicas o métodos basados en $\mathrm{ADN}$.

El diagnóstico de enfermedad por $C$. gattii puede ser elusivo. Las técnicas de cultivo tradicionales así como los inmunoensayos para antígeno capsular por criptococo no distinguen entre C. gattii y C.neoformans. Para diferenciar entre ambas especies se debe utilizar el agar de canavanina-glicina-bromotimol (CGB), en presencia de C.gatti dicho agar se vuelve azul ${ }^{(25)}$.

Serologías: los test serológicos para detectar antígenos de la cápsula de polisacárido en el suero y el líquido cefaloraquídeo son muy específicos en el diagnóstico de la enfermedad invasiva. Tanto la aglutinación por látex como los test de inmunoensayo con enzimas (ELISA) tienen una sensibilidad y especificidad mayor al 90\%. Con el adecuado procesamiento de las muestras, los falsos positivos son raros con títulos en líquido cefalorraquídeo mayores a 1:4. Los falsos positivos en test de aglutinación por latex son usualmente negativos en los ELISA, y viceversa.

Los falsos negativos pueden presentarse en la meningitis asintomática temprana $\mathrm{y}$ en la meningitis indolente crónica.

Los test serológicos sólo han sido validados para suero o líquido cefalorraquídeo, y no están recomendados para detectar antígenos de polisacárido en muestras de orina o lavado bronqueoloalveolar.
Los anticuerpos para C. neoformans pueden ser detectados durante la infección y son útiles para estudios epidemiológicos, pero debido a que muchos de estos pacientes están inmunocomprometidos, los títulos de anticuerpos son inconsistentes y generalmente no se utilizan para decisiones diagnósticas o terapéuticas.

Radiología: la radiografía de tórax en la criptococosis pulmonar puede demostrar varias características, incluyendo infiltrados difusos o locales, nódulos, linfadenopatías hiliares, cavitaciones y derrame pleural. En los pacientes con SIDA, el infiltrado intersticial difuso puede confundirse con una coinfección por Pneumocystis.

La tomografía axial computarizada (TAC) y la resonancia magnética nuclear (RMN) del cerebro son frecuentemente utilizadas en el manejo de la meningoencefalitis criptococóccica. Aproximadamente $50 \%$ de las TACs son normales en las infecciones del SNC. Sin embargo, la TAC puede revelar hallazgos tales como hidrocefalia, o nódulos múltiples o únicos que pueden captar o no captar medio de contraste. Los criptococomas pueden ser únicos o múltiples, y en algunas poblaciones (ej. pacientes con infección por C.gattii), pueden ocurrir en $25 \%$ de pacientes inmunocompetentes no portadores de VIH.

\section{Tratamiento}

Está claro que la meningitis criptococóccica es fatal sin tratamiento antifúngico.

Con base en las guías de práctica clínica para el manejo de la enfermedad criptococóccica, de la sociedad americana de enfermedades infecciosas ${ }^{(26)}$ se establecen numerosas pautas de tratamiento, de las cuáles las principales y que tienen mayor nivel de evidencia son:

\section{-Meningoencefalitis criptococóccica en pacientes VIH (terapia primaria; inducción y consolidación): anfotericina B deoxycolato $(0,7-1,0 \mathrm{mg} / \mathrm{Kg} / \mathrm{d}$ IV) más flucitosina $(100 \mathrm{mg} / \mathrm{kg} / \mathrm{d}$ VO dividido en cuatro dosis) por al menos 2 semanas; seguido de flucona- zol (400 mg [6 mg/kg] por día VO) por un mínimo de 8 semanas (recomendación 1A).}

-Meningoencefalitis criptococóccica en pacientes VIH (terapia supresiva, profiláctica): fluconazol $200 \mathrm{mg} \mathrm{c} / \mathrm{d}$ VO (recomendación IA). 
-Meningoencefalitis criptococóccica en pacientes receptores de transplantes: Anfotericina B liposomal (3-4 $\mathrm{mg} / \mathrm{kg} / \mathrm{d})$ o anfotericina B complejo lipídico $(5 \mathrm{mg} / \mathrm{kg} / \mathrm{d}$ IV) más flucitosina $(100$ $\mathrm{mg} / \mathrm{kg} / \mathrm{d}$ VO dividido en cuatro dosis) por al menos 2 semanas; seguido de fluconazol $(400-800 \mathrm{mg} / \mathrm{d}$ VO) por ocho semanas y fluconazol (200-400mg/d VO) por 6-12 meses (recomendación IIB).

-Meningoencefalitis criptococóccica en pacientes no VIH, no transplantados (terapia primaria; inducción y consolidación): anfotericina $\mathrm{B}$ deoxycolato $(0,7-1,0 \mathrm{mg} / \mathrm{Kg} / \mathrm{d} \mathrm{IV})$ más flucitosina $(100 \mathrm{mg} / \mathrm{kg} / \mathrm{d}$ VO dividido en cuatro dosis $)$ por al menos 4 semanas; luego consolidación con fluconazol $(400 \mathrm{mg} / \mathrm{d})$ por 8 semanas (recomendación IIB).

-Criptococomas cerebrales: anfotericina B deoxycolato $(0,7-1,0 \mathrm{mg} / \mathrm{Kg} / \mathrm{d} \mathrm{IV})$ más flucitosina $(100 \mathrm{mg} / \mathrm{kg} / \mathrm{d}$ VO dividido en cuatro dosis) por al menos 2 semanas; seguido de fluconazol (400 $\mathrm{mg}$ [6 mg/kg] por día VO) por un mínimo de 6 semanas (recomendación IIIB). Consolidación con fluconazol (400-800 mg/d VO) por al menos 6-18 meses. Terapias adyuvantes: esteroides si hay efecto de masa y cirugía si lesión es $>3 \mathrm{~cm}$.

-Criptococosis pulmonar (inmunosuprimidos): en todos los casos hacer punción lumbar para descartar afeccion SNC. Si los sintomas son leves-moderados, y no hay inmunosupresión profunda se recomienda fluconazol $(400 \mathrm{mg} / \mathrm{d}$ VO) por 6-12 meses (IIIB). Si los síntomas son severos o hay inmunosupresipon profunda $\mathrm{o}$ enfermedad diseminada se trata igual que la meningitis criptococóccica.

-Criptococosis pulmonar (no inmunosuprimidos): síntomas leves.moderados, fluconazol (400 $\mathrm{mg} / \mathrm{d}$ VO) por 6-12 meses. Si hay enfermedad severa se trata igual que meningitis criptococóccica. Se debe considerar punción lumbar para descartar afección SNC.

\section{Contexto nacional}

El primer caso de criptococosis en Costa Rica fue confirmado por Hidalgo y col. en $1960^{(27)}$. A su vez, Alice describe un caso costarricense de criptococosis meníngea fatal, diagnosticado mediante demostración de levaduras teñidas con tinta china en líquido cefaloraquídeo, en 1979 (28). En ninguno de los reportes de caso se men- ciona presencia de inmunosupresión en el huésped.

Desde entonces en relación a la criptococosis en Costa Rica, sólo han existido reportes aislados principalmente en pacientes portadores de infección por virus de inmunodeficiencia humana.

Según datos del Ministerio de Salud costarricense, la incidencia de infección por VIH es de aproximadamente 8 casos por cada 100000 habitantes ${ }^{(29)}$. Se desconoce la prevalencia de VIH en nuestro país, y dicha infección se ha catalogado como un problema de salud pública nacional.

Hasta el momento no existe ningún estudio epidemiológico en nuestro país que determine la prevalencia de infecciones por Cryptococcus sp. ya sea en pacientes inmunosuprimidos (VIH positivos, trasplantados órgano sólido, tratamiento inmunosupresor crónico) o inmunocompetentes.

Además se desconocen cuáles son las características epidemiológicas, clínicas y de respuesta al tratamiento que tienen nuestros pacientes con criptococosis, así como si existe alguna diferencia de dichas variable según el perfil inmunológico.

El conocimiento de lo anterior, permitiría comprender la presentación y comportamiento de dicha infección en nuestro país. Y de esta manera establecer medidas efectivas con el fin de mejorar la prevención, el diagnóstico y el manejo de dicha patología.

Además es necesario conocer cuál es la evolución de nuestros pacientes así como la respuesta al tratamiento brindado, más aún cuando $a$ priori impresiona que la morbimortalidad es amplia, más aún si se considera que no contamos con un fármaco de primera línea en el manejo de la criptococosis en el paciente inmunosuprimido como lo es la flucitosina.

\section{PROPÓSITO DEL ESTUDIO}

\section{Interrogante al estudiar:}

¿Cuáles son las características epidemiológicas, clínicas y de respuesta al tratamiento de los pacientes con diagnóstico de criptococosis en el Hospital San Juan de Dios? 
Población (características) : todos los pacientes con diagnóstico de Criptococosis, en el Hospital San Juan de Dios, período 2008-2012

a. Objeto de estudio: perfil epidemiológico, características clínicas, respuesta al tratamiento de pacientes con diagnóstico microbiológico de infección por criptococosis, en el Hospital San Juan de Dios, período 2008-2012.

b. Comparaciones : perfil epidemiológico, características clínicas y respuesta terapéutica de nuestros pacientes con criptococosis , comparados con lo reportado internacionalmente. Así como comparación entre pacientes VIH positivos y negativos

c. Resultados: perfil epidemiológico, características clínicas, valores de laboratorio, gabinete,morbilidad, mortalidad y respuesta terapéutica de los pacientes con criptococosis en el Hospital San Juan Dios.

2. Objetivo general: determinar el perfil epidemiológico, características clínicas y respuesta al tratamiento de los pacientes con criptococosis en el Hospital San Juan de Dios, período 2008-2012.

\section{Objetivos específicos:}

a. Determinar cuál es la especie más prevalente como etiología de la criptococosis.

b. Definir cuál es el órgano más afectado por el Cryptococcussp.

c. Establecer los factores de riesgo para el desarrollo de la criptococosis.

d. Determinar asociación entre antecedente de infección por virus de inmunodeficiencia humana, tratamiento antirretroviral y casos nuevos de criptococosis.

e. Establecer diferencias en la presentación clínica de la criptococosis entre pacientes VIH positivos vs VIH negativos.

d. Valorar la respuesta terapéutica a los antimicóticos y compararla entre pacientes VIH positivos vs VIH negativos.

e. Describir el tratamiento antibióticos concomitante en los pacientes con criptococosis. f. Determinar tipo de tratamiento antirretroviral, así como el momento de inicio en los pacientes con criptococosis e infección por VIH.

g. Comparar variables entre pacientes con criptococosis vivos y fallecidos.

h. Establecer factores predicitivos de sobrevida entre los pacientes con criptococosis.

\section{Materiales y métodos}

La presente investigación corresponde a un estudio descriptivo observacional, en el que se incluyeron todos los adultos con diagnóstico microbiológico de criptococosis en el Hospital San Juan de Dios, entre enero 2008 y diciembre del 2012, inclusive.

Con el fin de identificar a la población meta se acude al laboratorio de Micología del Hospital San Juan de Dios, donde se realiza una búsqueda en la base de datos interna del laboratorio. Todos los pacientes a los que se les identifica un cultivo positivo porCryptoccocussp. dentro del hospital, son registrados en dicha base de datos.

El diagnóstico de infección de Cryptococcussp. se realizó en el laboratorio de micología mediante cultivo de la muestra (líquido cefalorraquídeo, sangre, médula ósea, secreciones respiratorias, piel) en medio de Sabouraud. Posteriormente la especie de la levadura es identificada con el sistema Vitek ${ }^{\circledR}$ (bioMériux), el cual está basado en tecnología de fluorescencia y se compone de las tarjetas de análisis con 63 podocilos, una consola satélite para la recogida de información, un módulo incubador y un software que procesa la información (30). Dicho sistema mediante características bioquímicas de las levaduras permite identificar 6 especies de Cryptococcussp. (C. neoformans, C. albidus, $C$. laurentii, C. luteolus, C. terreus, C. uniguttulatus ).

Con base en dicha búsqueda se obtiene la lista preliminar de 71pacientes diagnosticados con criptococosis entre enero 2008 y diciembre 2012.

Posteriormente se buscan los respectivos expedientes en la oficina de Registros Médicos, y en el momento de la recolección de dichos expedientes clínicos, sólo se logran obtener de la Oficina de Registros Médicos un total de 33 expedientes, pues existieron 38 que no aparecieron por diferentes razones (pacientes fallecidos 
con expedientes microfilmados, expedientes sin guía o desaparecidos, expedientes que estaban en otro sitio diferente a la Oficina de Registros) (ver tabla I).

Tabla I. Expedientes obtenidos de la oficina de Registros Médicos HSJD a partir del total de pacientes con cultivo positivo por Cryptococcussp. entre el año 2008-2013

\begin{tabular}{|l|l|}
\hline & $\begin{array}{l}\text { Número de } \\
\text { expedientes }\end{array}$ \\
\hline $\begin{array}{l}\text { Totalidad de pacientes con } \\
\text { cultivo positivo por Crypto- } \\
\text { coccussp. } \\
\text { Expedientes no aparecidos } \\
\text {-Microfilmados (algu- }\end{array}$ & 31 \\
$\begin{array}{l}\text { nos de los pacientes falleci- } \\
\text { dos) -Expedientes sin guía o }\end{array}$ & 27 \\
desaparecidos & 5 \\
$\begin{array}{l}\text { la Oficina de Registros Médi- } \\
\text { cos Expedientes fuera de }\end{array}$ & 33 \\
Expedientes recolectados & 6 \\
\hline
\end{tabular}

De los 33 expedientes clínicos que se lograron obtener, todos cumplieron los criterios de inclusión y ninguno presentó los criterios de exclusión (ver tabla II y III).

Tabla II. Criterios de inclusión de los pacientes

a. Rango de edad: 18 años en adelante.

b. Género: masculino y femenino.

c. Etnia: cualquier etnia.

d. Pacientes con diagnóstico microbiológico, cultivo positivo por Cryptococcussp. en sangre, líquido cefalorraquídeo, médula ósea u otro tejido corporal.

e. Expediente cuente con la información necesaria que permita analizar los datos e incluirlos en el estudio.

Tabla III. Criterios de exclusión
a. Embarazo
b. Menores de edad.
c. Ausencia de diagnóstico microbiológico de criptococosis.

Posteriormente se procede a recopilar los datos de los 33 expedientes clínicos incluidos en el estudio. La información se recoge en un formulario diseñado personalmente por el investigador, con base a estudios epidemiológicos previos de criptococosis a nivel internacional ${ }^{(31,32)}$. (ver anexo 1. Hoja recolección de datos).

Se analizaron múltiples variables epidemiológicas, clínicas, de laboratorio y gabinete, así como de tratamiento; con el fin de caracterizar la criptococosis en nuestro medio y comparar como se manifiesta dicha enfermedad entre pacientes VIH positivos vs VIH negativos (ver tabla IV).

Tabla IV. Variables analizadas en el momento del diagnóstico inicial de la criptococosis, HSJD, período 2008-2012

a. Cualitativas nominales: sexo, nacionalidad, residencia, antecedente de $\mathrm{VIH}$, enfermedad autoinmune, transplante órgano sólido , cefalea, náuseas, vómitos, fiebre, alteración sensorio, tos, alteraciones visuales, pérdida peso, adenomegalias, alteraciones de la conducta, convulsiones, déficit motor, lesiones cutáneas, tinta china, Ag capsular LCR, Ag capsular suero, cultivo criptococo, radiografía tórax, TAC Cerebro (hidrocefalia, infarto cerebral, atrofia cerebral), clasificación de enfermedad (pulmonar, cerebral, diseminada, cutánea), tinta china en líquido cefalorraquídeo, tratamiento con anfotericina B, antirretrovirales, otros antibióticos brindados, drenaje múltiple de LCR, resultados terapia (éxito, falla, recaída, muerte).

b. Cuantitativas discretas: año de nacimiento, edad, fecha diagnóstico criptococosis.

c. Cuantitativas continuas: hemograma, electrolitos, glicemia, proteínas totales y fraccionadas, pruebas función renal, pruebas de función hepática, deshidrogenasa láctica, proteína $\mathrm{C}$ reactiva, $\mathrm{PCR}$, VES, CD4, carga viral VIH. 
Una vez llenados los formularios de recolección de información, los datos fueron ingresados a una base de datos en EPI Info 7 (CDC 2013), específicamente diseñada para esta investigación.

Se realizó una determinación de frecuencias y proporciones de las variables analizadas, y posteriormente se compararon los resultados entre los pacientes VIH positivos vs VIH negativos.

Las variables continuas se expresaron como promedios mas menos desviación estándar y se compararon mediante prueba de T-student Porr $_{3}$ otro lado, las variables categóricas fueron pơpẩ sadas mediante porcentajes, comparándolas mediante la prueba chi cuadrado o prueba exacta de Fisher según corresponde. Se utilizó un valor de $\mathrm{p} \leq 0,05$ que se consideró estadísticamente significativo.

Además se realizó un análisis de regresión logística para predicción de mortalidad tomando como variables predeterminadas el diagnóstico de VIH, presión de entrada $>25 \mathrm{cmH} 2 \mathrm{O}$ y tratamiento antirretroviral concomitante, lo anterior basados en estudios internacionales reportados previamente ${ }^{(33)}$.

Todos los análisis fueron realizados por meáliłimos 5 años, un total de 33 pacientes se encuentran del software estadístico IBM SPSS Statistics 22.0 .

Lo anterior contando con la aprobación del pacientes diagnosticados en el año 2008 ya fallecieron, un Comité Local de Bioética en Investigacion del Hospital San Juan de Dios (CLOBI). $\quad 83 \%$

Tabla VI. Características generales pacientes con criptococosis

\section{Resultados}

Con base en la lista preliminar obtenida de la base de datos del Servicio de Micología del Hospital San Juan de Dios se determinó que un total de 71 pacientes fueron diagnósticados con criptococosis entre enero 2008 y dicembre 2012. Con una tendencia hacia el aumento en la incidencia de casos por año. (ver tabla $\mathrm{V}$ y figura 3 ).

Tabla V. Número de pacientes diagnosticados con criptococosis por año

\begin{tabular}{|l|l|l|l|l|}
\hline 2008 & 2009 & 2010 & 2011 & 2012 \\
\hline $\mathbf{1 2}$ & 12 & 13 & 19 & 15 \\
\hline
\end{tabular}

\section{Numero de pacientes..}

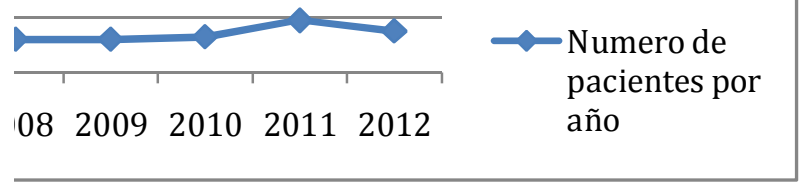

De estos 71 pacientes diagnosticados por criptococosis en los 


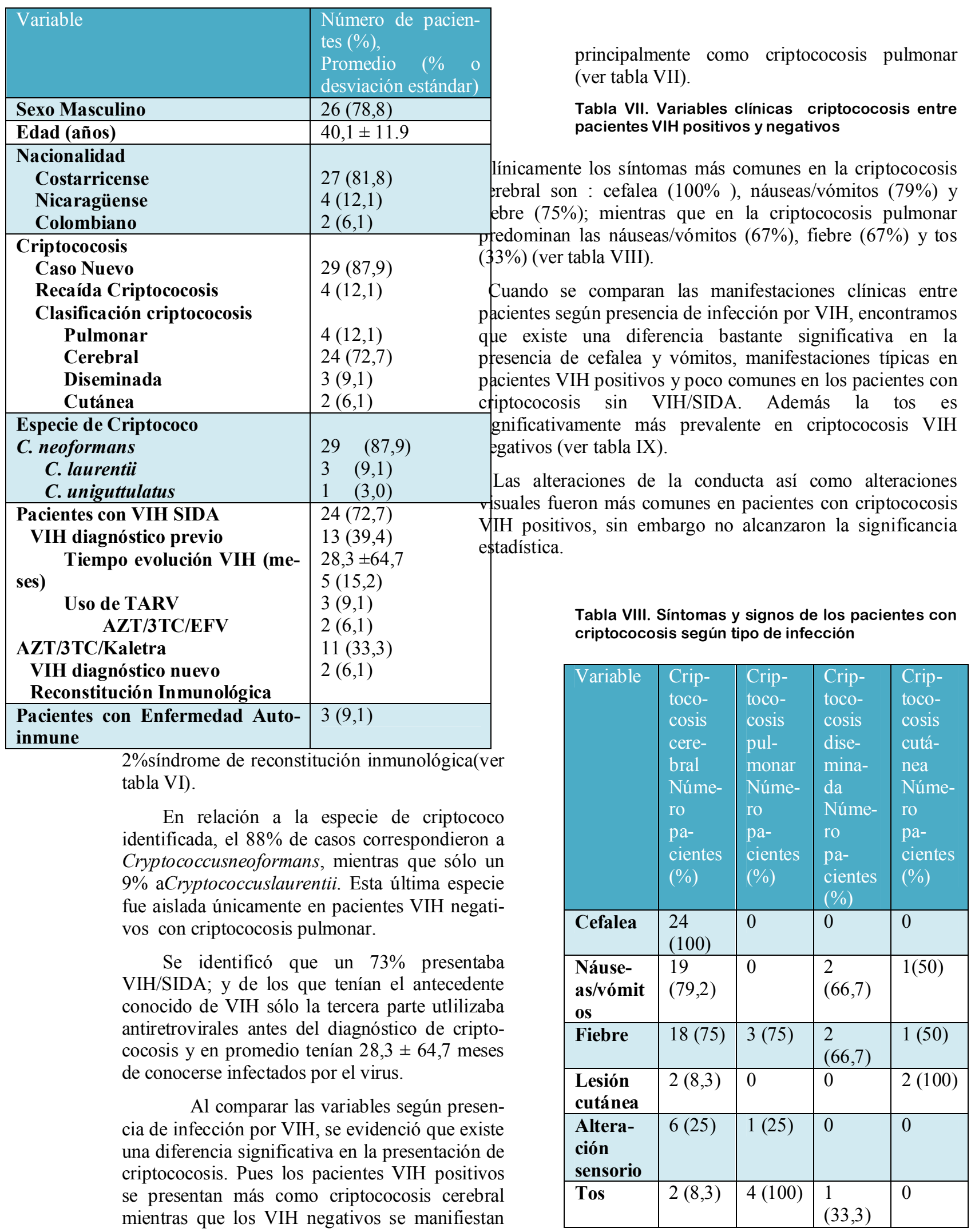




\begin{tabular}{|l|l|l|l|l|}
\hline $\begin{array}{l}\text { Altera- } \\
\text { ciones } \\
\text { visuales }\end{array}$ & $\begin{array}{l}7 \\
(29,2)\end{array}$ & 0 & 0 & 0 \\
\hline $\begin{array}{l}\text { Rigidez } \\
\text { nucal }\end{array}$ & $\begin{array}{l}3 \\
(12,5)\end{array}$ & 0 & 0 & 0 \\
\hline $\begin{array}{l}\text { Altera- } \\
\text { ciones } \\
\text { conduc- } \\
\text { ta }\end{array}$ & $\begin{array}{l}7 \\
(29,2)\end{array}$ & 0 & 0 & 0 \\
\hline $\begin{array}{l}\text { Convul- } \\
\text { siones }\end{array}$ & $\begin{array}{l}5 \\
(20,8)\end{array}$ & 0 & 0 & 0 \\
\hline $\begin{array}{l}\text { Déficit } \\
\text { Motor }\end{array}$ & $\begin{array}{l}3 \\
(12,5)\end{array}$ & 0 & 0 & 0 \\
\hline $\begin{array}{l}\text { Adeno- } \\
\text { patías }\end{array}$ & $\begin{array}{l}3 \\
(12,5)\end{array}$ & 0 & $\begin{array}{l}1 \\
(33,3)\end{array}$ & 0 \\
\hline $\begin{array}{l}\text { Pérdida } \\
\text { de Peso }\end{array}$ & $\begin{array}{l}12 \\
(50 \%)\end{array}$ & $1(25)$ & $\begin{array}{l}1 \\
(33,3)\end{array}$ & 0 \\
\hline
\end{tabular}

Tabla IX. Síntomas y signos de los pacientes con criptococosis según presencia de VIH

\begin{tabular}{|c|c|c|c|}
\hline Variable & $\begin{array}{l}\text { Número } \\
\text { de pacien- } \\
\text { tes con } \\
\text { Criptoco- } \\
\text { cosis } \\
\text { VIH nega- } \\
\text { tivos }(\%)\end{array}$ & $\begin{array}{l}\text { Número } \\
\text { de pacien- } \\
\text { tes con } \\
\text { Criptoco- } \\
\text { cosis VIH } \\
\text { positivos } \\
(\%)\end{array}$ & $\begin{array}{l}\mathrm{Va-} \\
\text { lor } \\
\text { de la } \\
\mathrm{p}\end{array}$ \\
\hline Cefalea & $2(22)$ & $22(91,7)$ & $\begin{array}{l}<0,0 \\
01\end{array}$ \\
\hline $\begin{array}{l}\text { Náuse- } \\
\text { as/vómitos }\end{array}$ & $3(33,3)$ & $19(79,2)$ & $\begin{array}{l}\mathbf{0 , 0 1} \\
3\end{array}$ \\
\hline Fiebre & $5(55,6)$ & $19(79,2)$ & $\begin{array}{l}0,17 \\
5\end{array}$ \\
\hline $\begin{array}{l}\text { Lesión cutá- } \\
\text { nea }\end{array}$ & $1(11,1)$ & $3(12,5)$ & $\begin{array}{l}0,91 \\
3\end{array}$ \\
\hline $\begin{array}{l}\text { Alteración } \\
\text { sensorio }\end{array}$ & $1(11,1)$ & $6(25,0)$ & $\begin{array}{l}0,38 \\
5\end{array}$ \\
\hline Tos & $4(44,4)$ & $3(12,5)$ & $\begin{array}{l}0,04 \\
6\end{array}$ \\
\hline $\begin{array}{l}\text { Alteraciones } \\
\text { visuales }\end{array}$ & 0 & $7(29,2)$ & $\begin{array}{l}0,06 \\
8\end{array}$ \\
\hline $\begin{array}{l}\text { Rigidez nu- } \\
\text { cal }\end{array}$ & 0 & $3(12,5)$ & $\begin{array}{l}0,26 \\
6 \\
\end{array}$ \\
\hline $\begin{array}{l}\text { Alteraciones } \\
\text { conducta }\end{array}$ & 0 & $7(29,2)$ & $\begin{array}{l}0,06 \\
8\end{array}$ \\
\hline $\begin{array}{l}\text { Convulsio- } \\
\text { nes }\end{array}$ & 0 & $5(20,8)$ & $\begin{array}{l}0,13 \\
7\end{array}$ \\
\hline $\begin{array}{l}\text { Déficit Mo- } \\
\text { tor }\end{array}$ & $1(11,1)$ & $2(8,3)$ & $\begin{array}{l}0,80 \\
5\end{array}$ \\
\hline Adenopatías & 0 & $4(16,7)$ & 0,19 \\
\hline
\end{tabular}

\begin{tabular}{|l|l|l|l|}
\hline & & & 1 \\
\hline $\begin{array}{l}\text { Pérdida de } \\
\text { Peso }\end{array}$ & $2(22,2)$ & $12(50)$ & $\begin{array}{l}0,15 \\
0\end{array}$ \\
\hline
\end{tabular}

Al analizar las variables de laboratorio, se identifica que en promedio los pacientes con criptococosis se manifiestan con anemia $(\mathrm{Hb}$ $11,2 \mathrm{~g} / \mathrm{dl}$; Hto $33 \%$ ), hiponatremia leve, y elevación discreta de reactantes de fase aguda (proteína $\mathrm{C}$ reactiva $3,8 \mathrm{mg} / \mathrm{dl}$ ).

En el momento del diagnóstico no presentaron alteraciones en los valores plasmáticos de potasio ni de calcio. Tampoco la infección se acompañaba de elevación en los valores de la deshidrogenasa láctica.

Cuando se compararon las poblaciones con y sin infección por VIH, se encontraron diferencias significativas:

-Los pacientes con criptococosis VIH negativos presentaron leucocitosis con neutrofilia absoluta, mientras que los VIH positivos manifestaban valores normales de leucocitos y neutrófilos.

-Se observó bandemia significativa en los pacientes VIH negativos en relación a los VIH positivos.

-Los pacientes con criptococosis VIH negativos tenían insuficiencia renal con patrón colestásico hepático, mientras que los VIH positivos no suelen manifestarse con alteraciones en función renal o hepática.

-En criptococosis VIH positivos se observó aumento en las proteínas totales a expensas del mayor número de globulinas.

Además al 56\% de los pacientes con criptococosis VIH negativos se les evidenció infiltrados pulmonares en la radiografía de tórax, mientras que este hallazgo sólo se presentó en el $4 \%$ de los VIH positivos, lo cual también fue estadísticamente significativo $(p<0,001)$.

En relación al estado inmunológico de los pacientes con criptococosis VIH positivos, estos presentaron en promedio un conteo de CD4 de $96 \pm 92,8 \mathrm{cel} / \mu \mathrm{L}$ y una carga viral $422521 \pm 1208$ 124 copias/ml. (Ver tabla X). 
Tabla $X$. Laboratorios y gabinete pacientes con criptococosis según presencia de infección por VIH

\begin{tabular}{|c|c|c|c|}
\hline Variable & $\begin{array}{l}\text { Criptococo- } \\
\text { sis paciente } \\
\text { VIH negati- } \\
\text { vo } \\
\text { Promedio } \\
\pm \text { DS }\end{array}$ & $\begin{array}{l}\text { Criptococo- } \\
\text { sis paciente } \\
\text { VIH positivo } \\
\text { Promedio } \\
\pm \text { DS }\end{array}$ & $\begin{array}{l}\text { Valor } \\
\text { de } p\end{array}$ \\
\hline \multicolumn{4}{|l|}{$\begin{array}{l}\text { Hemo- } \\
\text { grama }\end{array}$} \\
\hline $\begin{array}{l}\text { Hemoglo- } \\
\text { bina (g/dl) }\end{array}$ & $11,1 \pm 2,4$ & $11,3 \pm 1,9$ & 0,87 \\
\hline $\begin{array}{l}\text { Hemato- } \\
\text { crito (\%) }\end{array}$ & $33,3 \pm 7,2$ & $33,1 \pm 5,1$ & 0,95 \\
\hline $\begin{array}{l}\text { Leucos } \\
\text { (por }\end{array}$ & $\begin{array}{l}13225 \quad \pm \\
3548\end{array}$ & $6384 \pm 3231$ & $<0,001$ \\
\hline $\begin{array}{l}\mu \mathrm{L}) \text { Polim } \\
\text { orfonu- } \\
\text { cleares }\end{array}$ & $9538 \pm 3059$ & $4618 \pm 2674$ & $<0,001$ \\
\hline Linfocitos & $1522 \pm 1318$ & $911 \pm 477$ & 0,24 \\
\hline Monoci- & $630 \pm 464$ & $487 \pm 304$ & 0,32 \\
\hline tos & 0 & 0 & 0 \\
\hline Basófilos & $29,5 \pm 58,4$ & $54,4 \pm 154$ & 0,66 \\
\hline $\begin{array}{l}\text { Eosinófi- } \\
\text { los }\end{array}$ & $1144 \pm 1651$ & $\begin{array}{l}235,7 \\
375,6\end{array}$ & $\mathbf{0 , 0 1}$ \\
\hline Bandas & 309000 & $219733 \pm$ & 0,09 \\
\hline $\begin{array}{l}\text { Plaquetas } \\
\text { (por } \mu \mathrm{L})\end{array}$ & 174673 & 109475 & \\
\hline \multicolumn{4}{|l|}{$\begin{array}{l}\text { Bioquími- } \\
\text { ca }\end{array}$} \\
\hline $\begin{array}{l}\text { Sodio } \\
(\mathrm{mEq} / \mathrm{L})\end{array}$ & $135,7 \pm 4,7$ & $132,8 \pm 5,5$ & 0,21 \\
\hline $\begin{array}{l}\text { Potasio } \\
(\mathrm{mEq} / \mathrm{L})\end{array}$ & $3,7 \pm 0,6$ & $3,9 \pm 0,5$ & 0,26 \\
\hline $\begin{array}{l}\text { Cloruro } \\
(\mathrm{mEq} / \mathrm{L})\end{array}$ & $100,3 \pm 8,7$ & $103,7 \pm 4,1$ & 0,14 \\
\hline $\begin{array}{l}\text { Calcio } \\
\text { corregi- } \\
\text { do }(\mathrm{mg} / \mathrm{dl})\end{array}$ & $9,4 \pm 05$ & $9,4 \pm 0,5$ & 0,78 \\
\hline $\begin{array}{l}\text { Glicemia } \\
(\mathrm{mg} / \mathrm{dl})\end{array}$ & $128,2 \pm 28,9$ & $115,9 \pm 16,9$ & 0,21 \\
\hline $\begin{array}{l}\text { Proteínas } \\
\text { totales } \\
(\mathrm{g} / \mathrm{dl})\end{array}$ & $5,5 \pm 1,3$ & $7,27 \pm 1,2$ & 0,005 \\
\hline $\begin{array}{l}\text { Albúmi- } \\
\text { na (g/dl) } \\
\text { BUN }\end{array}$ & $2,57 \pm 0,9$ & $2,8 \pm 0,6$ & 0,38 \\
\hline $\begin{array}{l}(\mathrm{mg} / \mathrm{dl}) \\
\text { Creati- } \\
\text { nina } \\
(\mathrm{mg} / \mathrm{dl}) \\
\text { Bilirrubi- }\end{array}$ & $26,0 \pm 23,9$ & $11,9 \pm 4,2$ & 0,008 \\
\hline
\end{tabular}

\begin{tabular}{|c|c|c|c|}
\hline $\begin{array}{l}\text { na total } \\
(\mathrm{mg} / \mathrm{dl}) \\
\text { Bilirru- } \\
\text { bina dire- }\end{array}$ & $2,3 \pm 2,9$ & $0,5 \pm 0,2$ & 0,005 \\
\hline $\begin{array}{l}\text { cta } \\
\text { Bilirru- } \\
\text { bina indi- }\end{array}$ & $1,34 \pm 2,1$ & $0,2 \pm 0,1$ & 0,009 \\
\hline $\begin{array}{c}\text { recta } \\
\text { AST } \\
(\mathrm{UI} / \mathrm{L})\end{array}$ & $0,96 \pm 0,9$ & $0,3 \pm 0,1$ & 0,003 \\
\hline $\begin{array}{l}\text { ALT } \\
(\mathbf{U I} / \mathbf{L})\end{array}$ & $60,6 \pm 60,8$ & $39,3 \pm 33,1$ & 0,23 \\
\hline $\begin{array}{r}\text { GGT } \\
(\mathbf{U I} / \mathbf{L})\end{array}$ & $38,3 \pm 38,6$ & $36,9 \pm 32,0$ & 0,92 \\
\hline $\begin{array}{l}\text { FA (UI/L) } \\
\text { DHL }\end{array}$ & $115,4 \pm 146,1$ & $76 \pm 83,2$ & 0,3 \\
\hline (UI/L) & $256 \pm 387,7$ & $84,6 \pm 57,9$ & $\mathbf{0 , 0 4}$ \\
\hline $\begin{array}{l}\text { PCR } \\
\text { (mg/dl) }\end{array}$ & $258 \pm 131,5$ & $\begin{array}{l}192,2 \\
114,8\end{array} \quad \pm$ & 0,46 \\
\hline & $3,5 \pm 3,7$ & $4,1 \pm 3,3$ & 0,83 \\
\hline $\begin{array}{l}\text { Radio- } \\
\text { grafía de } \\
\text { tórax } \\
\quad \text { Infil- } \\
\text { trados } \\
\text { pulmona- } \\
\text { res }(\%)\end{array}$ & $5(55,6)$ & $1(4,2)$ & $<0,001$ \\
\hline $\begin{array}{l}\text { CD4 (por } \\
\mu \mathrm{L}) \\
\text { Carga } \\
\text { viral VIH } \\
(\text { co- } \\
\text { pias/ml) }\end{array}$ & |------------- & $\begin{array}{l}96 \pm 92,8 \\
422521 \\
208124\end{array} \quad \pm 1$ & "------- \\
\hline
\end{tabular}

Cuando se analiza la punción lumbar en criptococosis cerebral se evidencia que los hallazgos típicos son:

-Presión de entrada $>20 \mathrm{~cm} \mathrm{H} 2 \mathrm{O}$ (tendencia a mayor presión en $\mathrm{VIH}$ positivos pero sin llegar a alcanzar diferencia significativa).

-Hipoglucorraquia (48 mg/dl en VIH negativos y $39 \mathrm{mg} / \mathrm{dl}$ en VIH positivos; sin exitir diferencia significativa entre ambos grupos).

-Hiperproteinorraquia (alrededor de 96 mg(dl)

-Pleocitosis linfocitaria (119 leucos/ml en VIH negativos y $56 \mathrm{cel} / \mathrm{ml}$ en VIH positivos, la diferencia no es significativa)

-En relación a la tinta china, la misma tuvo para criptococosis meníngea una sensibilidad del 25\% en VIH negativos y de $58 \%$ en VIH positivos. 
El ADA tuvo un valor promedio de $2,8 \mathrm{U} / \mathrm{L}$ en VIH negativos y de 7,01 U/L en VIH positivos.

Se demostró que lo usual es que la criptococosismenpingea no se acompañe de TAC Cerebro alterado, pues esto solo se evidenció en el $20 \%$ de los VIH negativos y en el $30 \%$ de los VIH positivos. El hallazgo de anormalidad más frecuente fue la hidrocefalia $(66,7 \%)$ (Ver tabla XI)

Tabla XI. Valores de laboratorio en Criptococosis Cerebral, comparación entre pacientes VIH positivos vs VIH negativos

\begin{tabular}{|c|c|c|c|}
\hline Variable & $\begin{array}{l}\text { Criptoco- } \\
\text { cosis Ce- } \\
\text { rebral } \\
\text { VIH nega- } \\
\text { tivos } \\
\text { Promedio } \\
\pm \text { DS }\end{array}$ & $\begin{array}{l}\text { Criptoco- } \\
\text { cosis Ce- } \\
\text { rebral } \\
\text { VIH posi- } \\
\text { tivos } \\
\text { Promedio } \\
\pm \text { DS }\end{array}$ & $\begin{array}{l}\text { Va- } \\
\text { lor } \\
\text { de } p\end{array}$ \\
\hline $\begin{array}{l}\text { Líquido } \\
\text { cefalorra- } \\
\text { quídeo } \\
\text { Presión en- } \\
\text { trada } \\
\text { (cmH2O) } \\
\text { Glucosa } \\
\text { (mg/dl) } \\
\% \text { glucosa } \\
\text { en relación } \\
\text { plasma } \\
\text { Micropro- } \\
\text { teínas } \\
\text { (mg/dl) } \\
\text { Leucocitos } \\
\text { (cel/ml) } \\
\text { PMN } \\
\text { (\%) } \\
\text { Eritrocitos } \\
\text { (cel/ml) } \\
\text { ADA (U/L) } \\
\text { Tinta chi- } \\
\text { na positiva } \\
\text { (\%) }\end{array}$ & $\begin{array}{l}118,7 \pm \\
117,9 \\
1(33) \\
5,5 \pm 8,5 \\
2,8 \pm 1,3 \\
1(25)\end{array}$ & $\begin{array}{l}28,6 \quad \pm \\
13,9 \\
38,6 \quad \pm \\
16,1 \\
34,4 \quad \pm \\
14,7 \\
101,3 \quad \pm \\
127,7 \\
56 \pm 93 \\
2 \\
(16,7) \\
305 \pm 794 \\
7,01 \pm 3,1 \\
14(60,9)\end{array}$ & $\begin{array}{l}0,24 \\
0,55 \\
0,46 \\
0,16 \\
0,19\end{array}$ \\
\hline $\begin{array}{l}\text { TAC Cere- } \\
\text { bro (\%) } \\
\text { Anormal } \\
\text { LEO } \\
\text { Edema } \\
\text { cerebral } \\
\text { Hidroce- }\end{array}$ & $\begin{array}{l}1(20) \\
0 \\
0\end{array}$ & $\begin{array}{l}7(30) \\
4(16) \\
5(21)\end{array}$ & $\begin{array}{l}0,55 \\
0,29\end{array}$ \\
\hline
\end{tabular}

\begin{tabular}{|l|l|l|l|}
\hline $\begin{array}{c}\text { falia } \\
\text { Lesiones } \\
\text { isquémicas }\end{array}$ & 0 & $\begin{array}{l}1(33,3) \\
1(4,2)\end{array}$ & 0,73 \\
\hline
\end{tabular}

Entre los pacientes estudiados, al 100\% de los pacientes con criptococosis VIH positivos se les trató con anfotericina $\mathrm{B}$ deoxicolato, mientras que misma sólo se le brindó al $44 \%$ de los VIH negativos. Esta diferencia fue estadísticamente significativa (ver tabla XI).

Todos los pacientes VIH negativos tuvieron buena evolución (100\% éxito terapéutico), sin ningún fallecimiento, inclusive aunque no se les brindara tratamiento antimicótico.

En total fueron 5 pacientes con criptococosis VIH negativos a los que no se les brindó tratamiento con anfotericina, esto debido a:

-una femenina 20 años con criptococosis cutánea por $C$. uniguttulatus, si $\mathrm{n}$ inmunodeficiencias. La lesión solo se observó y desapareció sola.

-un masculino 33 años con criptococosis pulmonar en el contexto de un politrauma severo con ventilación mecánica prologada (en Unidad Cuidados Intensivos). El clínico no conoció nunca el reporte positivo de $C$. laurentii en esputo. Se le dieron 15 dias de fluconazol VO por candidemiasecuandariaCandidaparasilopsis. Evol ución favorable.

- un masculino 68 años con criptococosis pulmonar en el contexto de asmático severo con VMA prolongada (en Unidad Cuidados Intensivos). El clínico no conoció nunca el reporte positivo de $C$. laurentii en esputo. Recibió cefotaxime, vancomina y amikacina por neumonías nosocomiales. Evolución favorable.

-un masculino 64 años con criptococosis pulmonar en el contexto de politrauma severo con VMA prolongada (en Unidad Cuidados Inrtensivos). El clínico no conoció nunca el reporte positivo de $C$. laurentii en esputo. Recibió mpultiples esquemas antibióticos amplio espectro por sepsis nosocomiales. Evolución favorable.

-una femenina 54 años, diabética e hipertensa, con criptococoma pulmonar por C.neoformans, se manejó con fluconazol $400 \mathrm{mg} \mathrm{c} / \mathrm{d} \mathrm{VO}$ por 8 meses. Aún en control.

Por otro lado, entre los pacientes con criptococosis VIH positivos, se evidenció con la anfote- 
ricina $\mathrm{B}$ deoxicolato un $71 \%$ de éxito clínico, $25 \%$ muerte y $4 \%$ de falla clínica no mortal.

La dosis diaria de anfotericina $\mathrm{B}$ en este grupo de pacientes fue de $37 \pm 7,1 \mathrm{mg}$; con una dosis acumulada promedio de $733 \pm 367,5 \mathrm{mg}$.

Solo el $20 \%$ de los pacientes con criptococosis fueron tratados en la fase inicial de la terapia con anfotericina $\mathrm{B}$ más fluconazol parenteral, el resto fue manejado con anfotericina B como monoterapia..

Cuando se prescribió fluconazol IV asociado a la anfotericina B, a los VIH negativos se les dió una dosis diaria de $800 \mathrm{mg}$ IV mientras que en los VIH negativos se dieron $440 \pm 89 \mathrm{mg}$, diferencia estadísticamente significativa.

El tratamiento de consolidación con fluconazol fue de alrederor de $400 \mathrm{mg}$ c/d VO; en los VIH negativos se dió por $9,1 \pm 5,5$ meses y en los VIH positivos por 5,3 $\pm 5,4$ meses (sin diferencia significativa). (ver tabla XII).

Tabla XI. Tratamiento de criptococosis en pacientes con o sin infección VIH/SIDA

\begin{tabular}{|c|c|c|c|}
\hline Variable & $\begin{array}{l}\text { Pacientes } \\
\text { con Cripto- } \\
\text { cocosis } \\
\text { VIH nega- } \\
\text { tivos }\end{array}$ & $\begin{array}{l}\text { Pacientes } \\
\text { con Cripto- } \\
\text { cocosis } \\
\text { VIH positi- } \\
\text { vos }\end{array}$ & $\begin{array}{l}\mathrm{Va}- \\
\text { lor } \\
\text { de } \mathrm{p}\end{array}$ \\
\hline $\begin{array}{l}\text { Trata- } \\
\text { miento } \\
\text { Anfoteri- } \\
\text { cina B } \\
\quad \text { Sí }(\%)\end{array}$ & $4(44,4)$ & $24(100)$ & $\begin{array}{l}0,00 \\
1\end{array}$ \\
\hline 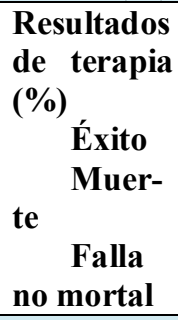 & $\begin{array}{l}4(100) \\
0 \\
0\end{array}$ & $\begin{array}{l}17(71) \\
6(25) \\
1(4,2)\end{array}$ & 0,16 \\
\hline $\begin{array}{l}\text { Dosis dia- } \\
\text { ria Anfo- } \\
\text { tericina B } \\
(\mathrm{mg})\end{array}$ & $40 \pm 9,1$ & $37 \pm 7,1$ & 0,55 \\
\hline $\begin{array}{l}\text { Dosis } \\
\text { Acumula- } \\
\text { da Anfote- }\end{array}$ & $705 \pm 364,8$ & $733 \pm 367,5$ & 0,88 \\
\hline
\end{tabular}

\begin{tabular}{|l|l|l|l|}
\hline $\begin{array}{l}\text { ricina B } \\
\text { (mg) }\end{array}$ & $2(22,2)$ & $5(20,8)$ & 0,75 \\
\hline $\begin{array}{l}\text { Trata- } \\
\text { miento } \\
\text { inicial } \\
\text { conjunto } \\
\text { con Fluco- } \\
\text { nazol IV } \\
\text { Sí (\%) }\end{array}$ & & & \\
\hline $\begin{array}{l}\text { Dosis dia- } \\
\text { ria Fluco- } \\
\text { nazol IV } \\
\text { (mg) }\end{array}$ & $800 \pm 0,0$ & $440 \pm 89,4$ & $\mathbf{0 , 0 0}$ \\
\hline $\begin{array}{l}\text { Días Flu- } \\
\text { conazol IV }\end{array}$ & $19 \pm 7,1$ & $13 \pm 2,7$ & 0,12 \\
\hline $\begin{array}{l}\text { Dosis Flu- } \\
\text { conazol } \\
\text { VO(mg) }\end{array}$ & $360 \pm 89,4$ & $450 \pm 143,3$ & 0,19 \\
\hline $\begin{array}{l}\text { Meses } \\
\text { Fluconazol } \\
\text { VO }\end{array}$ & $9,1 \pm 5,5$ & $5,3 \pm 5,4$ & 0,17 \\
\hline
\end{tabular}

Los pacientes con criptococosis recibieron múltiples terapias concomitantes, en su mayoría debido a complicaciones asociadas como infecciones nosocomiales e hipertensión endocraneana.

Los antibióticos más prescritos en orden descendente de frecuencia son: cefalosporinas, vancomicina y aminoglucósidos.

El único antibiótico que tuvo diferencia significativa entre pacientes con y $\sin \mathrm{VIH}$, fue el $\mathrm{TMP} / \mathrm{SMX}$, que fue prescrito $50 \%$ de los pacientes con SIDA y en ninguno de los VIH negativos.

Un $20 \%$ de los pacientes con criptococosis VIH positivos recibieron antifímicos, lo anterior corresponde a un total de 5 pacientes:

-Tres pacientes con TB pulmonar concomitante confirmada, los tres fallecieron en menos de 2 meses.

-Dos pacientes que recibieron empírica y transitoriamente antifímicos antes del diagnóstico confirmatorio de criptococosis cerebral. A los dos se les descartó la TB Meníngea, y tuivieron buena evolución.

La terapia antitoxoplasma que se brindó en el $12,5 \%$ de los pacientes VIH positivos fue empírica y transitoria, suspendida al diagnosticarse criptococosis cerebral. 
El $58 \%$ de los pacientes con criptococosis cerebral requirieron drenaje múltiple de LCR (más de tres drenajes), lo cual sólo se presentó en el $11 \%$ de los VIH negativos.

Tabla XIII. Tratamiento concomitante recibido en pacientes con criptococosis en pacientes con y sin $\mathrm{VIH} / \mathrm{SIDA}$

\begin{tabular}{|l|l|l|l|}
\hline Variable & $\begin{array}{l}\text { Pacientes } \\
\text { con Crip- } \\
\text { tococosis } \\
\text { VIH nega- } \\
\text { tivos } \\
(\%)\end{array}$ & $\begin{array}{l}\text { Pacientes } \\
\text { con Crip- } \\
\text { tococosis } \\
\text { VIH posi- } \\
\text { tivos } \\
(\%)\end{array}$ & $\begin{array}{l}\text { Va- } \\
\text { lor } \\
\text { de p }\end{array}$ \\
\hline $\begin{array}{l}\text { Cefalospori- } \\
\text { nas }\end{array}$ & $4(44,4)$ & $8(33,3)$ & 0,69 \\
\hline TMP/SMX & 0 & $12(50)$ & $\mathbf{0 , 0 1}$ \\
\hline $\begin{array}{l}\text { Carbapené- } \\
\text { micos }\end{array}$ & $2(22,2)$ & $3(12,5)$ & 0,59 \\
\hline Vancomicina & $4(44,4)$ & $4(16,7)$ & 0,17 \\
\hline Penicilina & $1(11,1)$ & $5(20,8)$ & 0,46 \\
\hline $\begin{array}{l}\text { Aminoglucó- } \\
\text { sidos }\end{array}$ & $2(22,2)$ & 0 & 0,06 \\
\hline Antifímicos & $1(11,1)$ & $5(20,8)$ & 0,46 \\
\hline $\begin{array}{l}\text { Antitoxo- } \\
\text { plasmosis }\end{array}$ & 0 & $3(12,5)$ & 0,54 \\
\hline $\begin{array}{l}\text { Drenaje } \\
\text { múltiple LCR }\end{array}$ & $1(11,1)$ & $14(58,3)$ & $\mathbf{0 , 0 1}$ \\
\hline
\end{tabular}

Al egreso se le brindó tratamiento antirretroviral al $79 \%$ de los pacientes con criptococosis VIH positivos (19 pacientes), a los 5 pacientes que no se les prescribió TARV fue debido a que fallecieron tempranamente.

De los TARV prescritos, los más comunes fueron la combinación AZT/3TC/EFV con un $41,6 \%$ y $\mathrm{ABC} / 3 \mathrm{TC} / \mathrm{EFV}$ con $20,8 \%$. En general el tratamiento antiretoviral se inició al mes del diagnóstico y tratamiento de la criptococosis (ver tabla XIV).

Tabla XIV. Tratamiento Antiretroviral de egreso en pacientes con criptococosis y VIH/SIDA

\begin{tabular}{|l|l|}
\hline $\begin{array}{l}\text { Tipo de Tratamiento Anti- } \\
\text { retroviral }\end{array}$ & $\begin{array}{l}\text { Número de pacien- } \\
\text { tes }(\%)\end{array}$ \\
\hline AZT/3TC/EFV & $10(41,6)$ \\
\hline
\end{tabular}

\begin{tabular}{|l|l|}
\hline ABC/3TC/EFV & $5(20,8)$ \\
\hline AZT/3TC/kaletra & $2(8,3)$ \\
\hline ABC/3TC/Kaletra & $2(8,3)$ \\
\hline
\end{tabular}

Cuando se comparan variables entres pacientes con criptococosis vivos y fallecidos se evidencia que el antecedente de VIH y la ausencia de TARV previo se asocian mayormente con los fallecidos (sin alcanzar una diferencia significativa). A su vez la ausencia de TARV fue estadísticamente significativo más común en los pacientes fallecidos en comparación con los vivos (ver tabla XV).

Tabla XV. Comparación entre pacientes con criptococosis vivos y fallecidos

\begin{tabular}{|l|l|l|}
\hline Variables & $\begin{array}{l}\text { Pacientes Fa- } \\
\text { llecidos }(\%)\end{array}$ & $\begin{array}{l}\text { Valor de la } \\
\mathrm{p}\end{array}$ \\
\hline $\begin{array}{l}\text { VIH negativo } \\
\text { VIH diagnósti- } \\
\text { co previo } \\
\text { VIH diagnósti- } \\
\text { co nuevo }\end{array}$ & $\begin{array}{l}2(33,3) \\
4(66,7)\end{array}$ & 0,06 \\
\hline TARV previo & $1(16,7)$ & 0,11 \\
\hline $\begin{array}{l}\text { TAC Cerebro } \\
\text { alterado }\end{array}$ & $2(33,3)$ & 0,57 \\
\hline $\begin{array}{l}\text { TARV al egre- } \\
\text { so } \quad 1(16,7)\end{array}$ & $\mathbf{0 , 0 5}$ \\
\hline \multicolumn{2}{|l}{ SI } & 1
\end{tabular}

Se realizó un análisis multivariado de factores predictores de mortalidad, en el cual se determinó que el diagnóstico de VIH se asocia significativamente a mayor mortalidad con un $\mathrm{OR}$ 12,79. Además la utilización de TARV se asocia significativamente a mayor sobrevida con un OR 0,015 .

Cuando se valoró la presión de entrada $>25$ $\mathrm{cmH} 2 \mathrm{O}$, existe una tendencia a mayor mortalidad en estos pacientes, pero sin alcanzar una diferencia significativa (ver tabla XVI).

Tabla XVI. Análisis multivariado de los factores predictores de mortalidad

\begin{tabular}{|l|l|l|l|}
\hline Variable & OR & IC 95\% & $\begin{array}{l}\text { Valor } \\
\text { de } p\end{array}$ \\
\hline $\begin{array}{l}\text { Diagnóstico de } \\
\text { VIH }\end{array}$ & 12,79 & $\begin{array}{l}1,63- \\
100,5\end{array}$ & $\mathbf{0 , 0 1 5}$ \\
\hline Presión entra- & 0,42 & $0,02-15$ & 0,063 \\
\hline
\end{tabular}




\begin{tabular}{|l|l|l|l|}
\hline da $>\mathbf{2 5 c m H 2 O}$ & & & \\
\hline $\begin{array}{l}\text { Tratamiento } \\
\text { antirretroviral } \\
\text { concomitante }\end{array}$ & $\mathrm{O}, 015$ & $0,001-$ & $\mathbf{0 , 0 1 4}$ \\
\hline
\end{tabular}

\section{DISCUSIÓN}

La criptococosis es una una infección micótica que se presenta especialmente en pacientes inmunocomprometidos ${ }^{(33)}$. En nuestro estudio se evidenció que el $72,7 \%$ de casos se asociaron a infección por virus inmunodeficiciencia humana, SIDA por definición.

Dentro del grupo sin VIH un 9,1\% de pacientes padecían enfermedades autoinmunes (un caso de miastenia gravis, un caso de poliangeitis microscópica y un caso de enfermedad inflamatoria intestinal secundaria a colitis ulcerativa), todos con inmunosupresión crónica a base de esteroides, azatioprina y/o ciclofosfamida. Además se reportó un caso de criptococosis cerebral en una paciente con cáncer papilar de tiroides metastásico. Lo anterior coincide con lo reportado a nivel internacional, que describe un incremento paulatino de casos de criptococosis entre pacientes con enfermedades autoinmunes o receptores de transplante de órgano sólido que reciben inmunosupresión crónica ${ }^{(32)}$.

En el presente estudio el $20 \%$ de casos de criptococosis ocurrieron en pacientes fenotípicamente normales a los que no se les demostró ninguna inmunosupresión. De manera interesante esta es la misma proporción de casos de criptococosis en inmunocompetentes que se ha reportado en series de otros centros ${ }^{(34)}$.

En cuanto a la incidencia de criptococosis por año, se evidenció que en los últimos 5 años ha existido una leve tendencia al aumento (figura $3)$, con 15 casos nuevos de criptococosis en el año 2012 en el hospital San Juan de Dios. Lo anterior reitera la necesidad de un ampliar el estudio epidemiológico de la criptococosis a nivel de todo el país, con el fin de determinar la incidencia nacional de esta enfermedad. Mas aún cuando según últimos reportes internacionales existe un incremento mundial en la incidencia anual de criptococosis entre pacientes con VIH, que va del 0,04 al $12 \%$ por año ${ }^{(35)}$.

Cabe recalcar que el promedio de edad en el que se diagnosticó la criptococosis fue de 40,1 \pm 11.9 años, ubicando esta enfermedad en un grupo de adultos jóvenes económicamente productivos.
Esto coincide con lo reportado en series internacionales $(31,32,37)$, y obliga a nuestras instituciones a tomar medidas de salud pública orientadas a la prevención de la enfermedad desde edades tempranas, probablemente en la adolescencia y de la mano con la prevención de la infección por el VIH.

La criptococosis cerebral constituyó la principal modalidad de presentación, representando un $72,7 \%$ de los casos, siendo significativamente más común entre los pacientes con VIH. Todos estos casos de meningitis fueron causados por la especie $C$. neoformans. Lo anterior evidencia que las infecciones por especies no-neoformans son raramente encontradas en el sistema nervioso central ${ }^{(36)}$. Así como el hecho que el C. neoformans muestra una predilección por invadir el sistema nervioso central causando meningitis o meningoencefalitis en $77-86 \%$ de los pacientes con SIDA ${ }^{(37)}$.

Por otro lado, la criptococosis pulmonar sólo se presentó en pacientes sin VIH, y sin ninguna inmunodeficiencia demostrada. De los 4 casos identificados con infección a nivel respiratorio, el $75 \%$ fue debido a $C$. laurentii y el $25 \%$ a $C$. neoformans. Inclusive todos los casos causados por $C$. laurentii no se diagnosticaron mientras el paciente estuvo ingresado a nivel hospitalario y resolvieron sin terapia con anfotericina B. Lo anterior respalda el hecho que las infecciones humanas causadas por especies no-neoformans son muy poco comunes y pobremente documentadas ${ }^{(5,6)}$. Además el único paciente con C.neoformans en pulmón se manifestó como un hallazgo incidental de un criptococoma, típica manifestación en inmunocompetentes.

Se encontraron diferencias estadísticamente significativas en cuanto a las características clínicas de la criptococosis entre pacientes según presencia de VIH. En pacientes con SIDA existe mayor cefalea así como náuseas y vómitos, mientras que en los $\mathrm{VIH}$ negativos existe más tos. Lo anterior refleja el hecho en la inmunosupresión, en este caso el VIH, condiciona una mayor presencia de criptococosis cerebral. Esto ya ha sido demostrado en estudios previos ${ }^{(31,32,}$ 33)

En cuanto a las variables de laboratorio y gabinete, estas no han sido reportadas en los principales estudios epidemiológicos de criptococosis a nivel internacional ${ }^{(31,32,33,35,37)}$ por lo que co- 
bra relevancia lo evidenciado por nuestro estudio. Los pacientes evidenciaron anemia con un valor promedio de $\mathrm{Hb} .11,2 \mathrm{~g} / \mathrm{dl}$ y Hto $33 \%$, sin leucopenia ni trombocitosis. Inclusive al comparar los pacientes VIH negativos vs VIH positivos, los primeros presentaron leucocitosis, neutrofilia y bandemia, lo cual no se presentó en los pacientes con SIDA que tendían a estar más bien linfopénicos. Estas diferencias fueron estadísticamente significativas.

Desde el punto vista bioquímico los VIH positivos presentaron hiponatremia con un valor de sodio promedio en $132,8 \pm 5,5$ y los VIH negativos manifestaron una natremia en el límite inferior normal. Esto ya ha sido reportado en casos aislados, donde se han planteado como causas la secreción inapropiada de hormona antidiurética y el síndrome de célula enferma ${ }^{(38)}$.

Comparativamente los pacientes sin VIH presentaron elevaciones mayores de: nitrógeno ureico, creatinina, bilirrubinas y fosfatasa alcalina. Todos con valores significativamente mayores a los presentados en los pacientes con SIDA, esto traduce mayor afección renal y hepática en los VIH negativos. Esto puede corresponder al hecho que los pacientes inmunocompetentes que desarrollan criptococosis tienen la capacidad de desencadenar una respuesta inmunológica sistémica más intensa ante la infección que los individuos con SIDA. A pesar de lo anterior, los pacientes VIH positivos tienen una probabilidad de muerte significativamente mayor.

Es de importancia evidenciar que los pacientes con criptococosis estudiados no elevaron los niveles de deshidrogenasa láctica, lo cual es importante debido a que existen otras patologías oportunistas que sí lo hacen de manera considerable, como la neumocistosis, histoplasmosis y tuberculosis.

Los infiltrados pulmonares en la radiografía de tórax se presentaron en el 55\% de los VIH negativos y sólo en el $4,2 \%$ de los VIH positivos. Esta diferencia fue estadísticamente significativa. Lo anterior correlaciona con reportes previos que enunciaban que las presentaciones radiológicas son variadas e inespecíficas, y están influenciadas por el estado inmunólogico subyacente del huésped ${ }^{(39)}$.

En promedio los pacientes con SIDA que desarrollaron criptococosis tenían un conteo de CD4 en $96 \pm 92,8$, con cargas virales muy elevadas. Lo cual habla de una inmunidad celular severa- mente comprometida y de una infección por VIH en estadío avanzado.

Cuando se analizó el líquido cefalorraquídeo se encontraron como hallazgos característicos la elevación en la presión de entrada, hipoglucorraquia, hiperproteinorraquiay pleocitosis linfocitaria. Sin encontrar diferencias significativas entre los VIH negativos y positivos. Dichos hallazgos en el LCR correlacionan con la descripción típica de la meningitis criptococóccica ${ }^{(4,28,31)}$.

El valor del ADA en el LCR tuvo un valor promedio de 2,8 U/L en VIH negativos y de 7,01 $\mathrm{U} / \mathrm{L}$ en VIH positivos. Considerando que el valor corte de ADA normal en el líquido cefalorraquídeo según INCIENSA es $<5 \mathrm{U} / \mathrm{L}$, se puede establecer que la criptococosis meníngea puede dar un falso positivo en dicho valor, pues a ninguno de estos pacientes se les demostró tuberculosis meníngea, a pesar de los estudios pertinentes. La elevación del ADA como falso positivo para tuberculosis fue recientemente reportada en un caso de pleuritis criptocóccica en un paciente con SIDA ${ }^{(40)}$. Además un pequeño estudio cohorte que utilizó un valor de $<6 \mathrm{U} / \mathrm{L}$ de ADA como normal en líquido cefalorraqúideo, evidenció que puede existir un traslape entre meningitis tuberculosa con meningitis criptococóccica o meningitis bacteriana aguda, especialmente cuando los niveles de ADA estaban levemente elevados ${ }^{(41)}$. Por lo que en pacientes VIH positivos valores de ADA en LCR entre 5 y $10 \mathrm{UI} / \mathrm{L}$ deben ser interpretados con cautela, pues podrían corresponder a falsos positivos.

Llama la atención la escasa sensibilidad encontrada de la tinta china para el diagnóstico de criptococosis cerebral, pues correspondió a $25 \%$ en VIH negativos y $58 \%$ en VIH positivos. En otras series se reporta una sensibilidad de entre 70 y $90 \%$, siendo aún mayor en pacientes con SIDA $^{(4,42)}$. Esto debe analizarse en el contexto de que la prueba de tinta china es inherente a la experiencia del observador, así como a la adecuada manipulación y cantidad de la muestra. Independientemente de estos factores, los cuales deben fortalecerse, y en vista de la baja sensibilidad de la prueba, se recomienda que ante la sospecha de criptococosismenigea se realicen pruebas complementarias diagnósticas como la detección del antígeno capsular del critpococo mediante aglutinación con látex, así como el cultivo respectivo.

El tratamiento antimicótico es fundamental en los pacientes con SIDA y criptococosis cerebral, 
sin el mismo prácticamente todos evolucionan hacia la muerte ${ }^{(31)}$. En nuestro estudio el $100 \%$ de los pacientes con criptococosis y SIDA recibieron tratamiento con anfotericina $\mathrm{B}$ deoxicolato ; mientras que dicha terapia sólo se brindó en el $44 \%$ de los pacientes VIH negativos. Dicha diferencia fue estadísticamente significativa. Ninguno de los pacientes VIH negativos falleció, sin embargo un $30 \%$ de pacientes con SIDA murieron o tuvieron falla terapéutica.

El éxito de la fase de inducción con anfotericina $\mathrm{B}$ como monoterapia fue del $70 \%$ entre los pacientes con SIDA, sin embargo cabe resaltar que dicho "éxito" se determinó únicamente utilizando el criterio clínico, en ningún caso se realizaron punciones lumbares control que determinaran esterilización del líquido. No existen registros previos que utilicen solo el criterio clínico a la hora de determinar la eficacia de la anfotericina $\mathrm{B}$ como monoterapia en criptococosis meníngea ${ }^{(31,32)}$. La combinación de anfotericina $\mathrm{B}$ con 5-fluorocitosina (5-FC) por dos semanas ha demostrado actividad fungicida mayor y más rápida comparado con la Anfotericina B sola ${ }^{(43)}$; además un estudio prospectivo francés también demostró que el mejor régimen como terapia de inducción es la combinación de Anfotericina B con 5-FC ${ }^{(44)}$. Por lo anterior, considerando que el 30\% de nuestros pacientes con criptococosis y SIDA fallecen tempranamente a pesar de monoterapia con anfotericina $\mathrm{B}$, se debe considerar agregar la 5-fluorocitosina en la fase de inducción, aprovechando su demostrada efectividad en la terapia combinada.

Se evidenció diferencia significativa en la dosis empleada de fluconazol IV entre pacientes con y sin infección por VIH. Cuando se prescribió fluconazolparenteral como coadyuvante a la anfotericina B en la terapiade inducción, se dieron $800 \mathrm{mg}$ diarios de fluconazol IV en los VIH negativos (2 pacientes) y $400 \mathrm{mg}$ IV en los VIH positivos (5 pacientes). Cabe resaltar con estos 2 casos de criptococosis en VIH negativos correspondieron a pacientes en shock séptico secundario a criptococosis diseminada, lo cual justificó las altas dosis de azoles.

En todo estudio es importante comparar a la población viva con la fallecida. Entre los pacientes muertos, se evidenció una presencia mayor de infección por VIH (aunque no fue estadísticamente significativa) y un menor uso de TARV al egreso (que sí fue estadísticamente significativo). A su vez, con base a estudios previos en cripto- $\operatorname{cocosis}^{(33)}$, se realizó un análisis multivariado de factores predictores de mortalidad y se identificó que el diagnóstico de VIH correlaciona fuertemente como predictor de mortalidad con un OR 12,79 y una $\mathrm{p} 0,015$.

Además, la utilización de TARV disminuye la mortalidad con un OR 0,015 y una p 0,014.

Lo anterior correlaciona con la literatura científica internacional $y$ respalda el hecho que la corrección de la inmunodeficiencia celular de fondo es fundamental en el manejo y sobrevida del paciente con criptococosis ${ }^{(33,35)}$.

\section{CONCLUSIÓN}

1. Entre los pacientes con criptococosis el $78,8 \%$ son hombres.

2. La criptococosis se diagnosticó a una edad promedio de 40,1 \pm 11.9 años.

3. El 87,9 \% de los casos de criptococosisfueron diagnósticos de novo, mientras que el $12,1 \%$ fueron recaídas.

4. $\mathrm{Al} 80 \%$ de los pacientes con criptococosis se les evidenció algún tipo de inmunodeficiencia. El 72,7\% tenían SIDA, el 9,1\% enfermedad autoinmune, y el 3\% cáncer metastásico.

5. En los pacientes VIH positivos la modalidad de presentación más común de criotococosises la cerebral, mientras que en los VIH negativos es la pulmonar. Esto fue estadísticamente significativo.

6. En relación a los síntomas y signos, se evidenció que la criptococosis en pacientes con SIDA se manifiesta principalmente con cefalea $(100 \%)$, náuseas/vómitos $(79,2 \%)$ fiebre $(79,2 \%)$. Mientras que en VIH negativos lo más común es tos $(44,4 \%)$ y fiebre $(55,6 \%)$. Las diferencias fueron estadísticamente significativas.

7. En general los pacientes con criptococosis presentan anemia, con un valor promedio de Hb. $11,2 \mathrm{~g} / \mathrm{dl}$ y Hto $33,2 \%$.

8. Al comparar los pacientes VIH negativos con los VIH positivos, los primeros presentaron leucocitosis, neutrofilia y bandemia , lo cual no se presentó en los pacientes con SIDA que tendían a estar más bien linfopé- 
nicos. Estas diferencias fueron estadísticamente significativas.

9. Los pacientes con criptococosis cerebral y SIDA presentan hiponatremia, con un valor promedio de $132,8 \pm 5,5 \mathrm{mEq} / \mathrm{L}$.

10. Comparativamente los pacientes sin VIH presentaron elevaciones mayores de: nitrógeno ureico, creatinina, bilirrubinas y fosfatasa alcalina. Todos con valores significativamente mayores a los presentados en los pacientes con SIDA.

11. En los pacientes con criptococosis no se evidenció una elevación en los valores de deshidrogenasa láctica.

12. Los infiltrados pulmonares en la radiografía de tórax se presentaron en el $55 \%$ de los VIH negativos y sólo en el 4,2\% de los VIH positivos. Esta diferencia fue estadísticamente significativa.

13. En promedio los pacientes con SIDA que desarrollaron criptococosis tenían un conteo de CD4 en $96 \pm 92,8$ cél $/ \mu \mathrm{L}$.

14. Cuando se analizó el líquido cefalorraquídeo en criptococosis cerebral se encontraron como hallazgos característicos: elevación en la presión de entrada, hipoglucorraquia, hiperproteinorraquia y pleocitosis linfocitaria. Sin encontrar diferencias significativas entre los VIH negativos y positivos.

15. La tinta china demostró una escasa sensibilidad para el diagnóstico de criptococosis cerebral, pues correspondió a $25 \%$ en VIH negativos y $58 \%$ en $\mathrm{VIH}$ positivo.

16. El valor del ADA en el LCR tuvo un valor promedio de 2,8 U/L en VIH negativos y de 7,01 U/L en VIH positivos. Con base en dichos valores, se puede establecer que la criptococosiscerebral puede dar falsos positivos para TB meníngea cuando la elevación del ADA es leve.

17. El $100 \%$ de los pacientes con criptococosis y SIDA recibieron tratamiento con anfotericina B deoxicolato ; mientras que dicha terapia sólo se brindó en el $44 \%$ de los pacientes VIH negativos. Dicha diferencia fue estadísticamente significativa.

18. Ninguno de los pacientes VIH negativos falleció, sin embargo un $30 \%$ de pacientes con SIDA murieron o tuvieron falla terapéutica.

19. Todos los pacientes con SIDA, tuberculosis y criptococosis fallecieron en menos de un mes del diagnóstico de la infección por Cryptococcussp.

20. Se debe considerar agregar la 5fluorocitosina como parte del tratamiento en la fase de inducción, aprovechando su demostrada efectividad en la terapia combinada con anfotericina B.

21. El análisis multivariado de factores predictores de mortalidad identificó que el diagnóstico de VIH correlaciona fuertemente como predictor de mortalidad con un OR 12,79, y que la utilización de TARV disminuye la mortalidad con un OR 0,015. Ambos con $\mathrm{p}$ estadísticamente significativa.

\section{AGRADECIMIENTOS}

Se le agradece al Dr. Allan Ramos Esquivel, especialista en Medicina Interna y Master en Epidemiología Clínica, por su importante colaboración en la fase de análisis estadístico de la investigación.

\section{BIBLIOGRAFÍA}

1. Sanfelice F. Contributo alla morfologia e biologia dei blastomiceti che si sviluppano nei succhi di alcuni frutti. Ann d'Igiene. 1894;4:463-495.

2. Buschke A. Uebe reine durch coccidien hervorge rufene krankheit des menschen. Dtsch Med Wochenschr. $1895 ; 21: 14$

3. Benham RW. Cryptococcosis and blastomycosis. Ann N Y Acad Sci. 1950;50:1299-1314

4. Prefect J. Cryptococcus neoformans. Infectious Diseases and Their Etiologic Agents. Mandell: Mandell, Douglas, and Bennett's Principles and Practice of Infectious Diseases, 7th ed. 2009. 
5. Luna T Lusins J. Cryptococcus albidus meningitis. South Med J. 1973;66:1230.

6. Kromery V Kunova A y Mardiak J. Nosocomial Cryptococcus laurentii fungemia in a bone marrow transplant patient after prophylaxis with ketoconazole successfully treated with oral fluconazole. Infection. 1997;25:130.

7. Franzot SP Salkin IF y Casadevall $A$. Cryptococcus neoformans var. grubii: separate varietal status for Cryptococcus neoformans serotype $A$ isolates. $\mathrm{J}$ Clin Microbiol 1999; 37:838.

8. Kwon-Chung KJ Boekhout T Fell JW y Diaz M. Proposal to conserve the name Cryptococcus gatii against $C$. hondurianus and C. bacillisporus (Basidiomycota, Hymenomycetes, Tremellomycetiadae). Taxon 2002; 51:804.

9. Speed B y Dunt D. Clinical and host differences between infections with the two varieties of Cryptococcus neoformans. Clin Infect Dis 1995; 21:28.

10. Kwon-Chung KJ y Rhodes JC. Encapsulation and melanin formation as indicators of virulence in Cryptococcus neoformans. Infect Immun 1986; $51: 218$.

11. Polacheck I Platt Y y Aronovitch J. Catecholamines and virulence of Cryptococcus neoformans. .Infect Immun 1990; 58:2919.

12. Wang Y Aisen P y Casadevall A. Cryptococcus neoformans melanin and virulence: mechanism of action. Infect Immun 1995; 63:3131.

13. Emmons CW. Saprophytic sources of Cryptococcus neoformans associated with the pigeon (Columba livia). Am J Hyg 1955; 62:227.

14. Ellis DH y Pfeiffer TJ. Natural habitat of Cryptococcus neoformans var. gattii.J Clin Microbiol 1990; 28:1642.

15. Pfeiffer TJ y Ellis DH. Environmental isolation of Cryptococcus neoformans var. gattii from Eucalyptus tereticornis. J Med Vet Mycol 1992; 30:407.

16. Kidd SE Hagen F Tscharke RL et all. $A$ rare genotype of Cryptococcus gattii caused the cryptococcosis outbreak on Vancouver Island (British Columbia,
Canada). Proc Natl Acad Sci U S A 2004; 101:17258.

17. Newberry WM Jr Walter JE Chandler JW Jr et all. Epidemiologic study of Cryptococcus neoformans. Ann Intern Med. 1967;67:724-732

18. Chen LC Goldman DL y Doering TL. Antibody response to Cryptococcus neoformans proteins in rodents and humans. Infect Immun. 1999;67:22182224.

19. Clumeck N Sonnet J Taelman H et all. Acquired immunodeficiency syndrome in African patients. $\mathrm{N}$ Engl J Med. 1984;310:492-497.

20. Kontoyiannis DP Peitsch WK y Reddy BT. Cryptococcosis in patients with cancer. Clin Infect Dis. 2001;32:145150.

21. Husain A Wagener MM y Singh N. Cryptococcus neoformans infection in organ transplant recipients: Variables influencing clinical characteristics and outcome. Emerg Infect Dis. 2001;7:375381.

22. Singh N Gayowski T Wagener MM et all. Clinical spectrum of invasive cryptococcosis in liver transplant recipients receiving tacrolimus. ClinTranspl. 1997;11:66-70.

23. Baker RD. The primary pulmonary lymph node complex of cryptococcosis. Am J Clin Pathol. 1976;65:83-92.

24. Perfect JR. Cryptococcosis. Infect Dis Clin North Am. 1989;3:77-102.

25. Kwon-Chung KJ Polacheck I y Bennett JE. Improved medium for separation of Cryptococcus neoformansvar. neoformans(serotypes $B$ and $D$ ) and Cryptococcus neoformansvar. gattii (serotypes $B$ and $C$ ). J ClinMicrobiolol1982; 15: 535-7.

26. Perfect JR Dismukes WE Dromer F et all. Clinical Practice Guidelines for the Managementof Cryptococcal Disease: 2010 Update by the InfectiousDiseases Society of America. IDSA Guidelines. ClinInf Dis 1;50(3): 291-322.

27. Hidalgo W Céspedes R Suárez A Hernández V y Morera P. Criptococosis. Estudio del primer caso confirmado en Costa Rica .Acta Med. Cost.1960 3(3): 221-235. 
28. Alice Madriz E. Criptococosis. Revista Médica de Costa Rica XLVI 1979 (467): 91-92.

29. Situación de VIH-SIDA y Plan Estratégico Nacional de Salud. Ministerio Salud de Costa Rica. Diciembre 2010.

30. Linares MJ y Solís F. Identificación de levaduras. Asociación Española de Micología. Revista Iberoamericana de Micología. 2007: 11-1, 11-20.

31. Antinori S. New Insights into HIV/SIDA-Associated Cryptococcosis. ISRN AIDS. 2013;2(25): 2-22.

32. Pappas G. Cryptococcal infections in non-HIV-infected patients. Transactions of the America Clinical and Climatological Association.2013(124): 61-79.

33. Brizendine KD Baddley JW y Pappas PG. Predictors of Mortality and Differences in Clinical Features among Patients with Cryptococcosis According to Immune Status. PLos ONE2013; 8(3): e60431.

34. Pappas PG Perfect JR Cloud GA, et all. Cryptococcosis in human immunodeficiency virus-negative patients in the era of effective azole therapy. Clin Infect Dis 2001; 33 (5): 690-9.

35. Park BJ Wannemuehler KA Marston BJ et all. Estimation of the current global burden of cryptococcal meningitis among persons living with HIV/AIDS. AIDS2009 20; 23(4):525-30.

36. Khawcharoenporn $\mathrm{T}$ Apisarnthanarak A y Mundy LM. Non neoformanscryptococcal infections: a systematic review. Infection2007 35(51):51-58.

37. Bratton EW Husseini EI Chastain CA et all. Comparison and temporal trends of three groups with cryptococcosis: HIVinfected, solid organ transplant, and HIV-negative/non-transplant. PLoS One, 2012;7(8): e43582.

38. Momi J Tang C Abcar AC et all. Hyponatremia in a patient with cryptococcal meningitis: syndrome of inappropriate antidiuretic hormone (SIADH) or cerebral salt wasting (CSW)? Journal of Hospital Medicine.2010;5(3): 193-195.

39. Jarvis JN y Harrison TS. Pulmonary cryptococcosis. SeminRespirCrit Care Med. 2008;29(2): 141-150.
40. Yoshino Y Kitazawa T Tatsuno K Ota Y y Koike K. Cryptococcalpleuritis containing a high level of adenosine deaminase in a patient with AIDS: a case report. Respiration 2010;79(2): 153-6.

41. Eintracht S. et all. Analysis of adenosine deaminase isoenzyme-2 (ADA2) in cerebrospinal fluid in the diagnosis of tuberculousmeningitis.JNeurolNeurosurg Psychiatry2000;(69): 137-38.

42. Trombetta L Poustis G y Bocassi A. CSF in patients with AIDS associated cryptococcosis. Actabioquímicaclínicalatinoamericana. 2008;42(1): 61-64.

43. Brouwer A Rajanuwong A Chierakul W et all. Combination antifungal therapies for HIV-associated cryptococcal meningitis: a randomized trial. Lancet 2004; 29(363): 1764-1767.

44. Dromer F Mathouline-Pélissier O and the French Cryptococcus Study Group. Determinants of disease presentation and outcome during cryptococcosis: the CryptoA/D study. PLoS Medicine 2007 4(2): e21.

\section{CONFLICTO DE INTERÉS Y/O AGRADE- CIMIENTOS}

Los autores declaran que no existió ningún conflicto de interés en el presente reporte. 